\title{
Review of Cryptosporidium and Giardia in the eastern part of Europe, 2016
}

Judit Plutzer ${ }^{1}$, Brian Lassen 2,3 , Pikka Jokelainen ${ }^{2,4,5}$, Olgica Djurković-Djakovićc ${ }^{6}$, István Kucsera7, Elisabeth Dorbek-Kolin²,

Barbara Šoba $^{8}$, Tamás Sréter ${ }^{9}$, Kálmán Imre ${ }^{10}$, Jasmin Omeragi ${ }^{11}$, Aleksandra Nikolić ${ }^{6}$, Branko Bobić ${ }^{6}$, Tatjana Živičnjak ${ }^{12}$,

Snježana Lučinger ${ }^{12}$, Lorena Lazarić Stefanović ${ }^{13}$, Jasmina Kučinar ${ }^{13}$, Jacek Sroka ${ }^{14}$, Gunita Deksne ${ }^{15}$, Dace Keidāne ${ }^{16}$, Martin Kváč́c ${ }^{17,18}$, Zuzana Hůzováa ${ }^{19}$, Panagiotis Karanis ${ }^{20,21}$

1. Department of Water Hygiene, National Public Health Institute, Budapest, Hungary

2. Department of Basic Veterinary Sciences and Population Medicine, Institute of Veterinary Medicine and Animal Science, Estonian University of Life Sciences, Tartu, Estonia

3. Department of Veterinary Disease Biology, University of Copenhagen, Frederiksberg, Denmark

4. Faculty of Veterinary Medicine, University of Helsinki, Helsinki, Finland

5. Department of Bacteria, Parasites \& Fungi, Infectious Disease Preparedness, Statens Serum Institut, Copenhagen, Denmark

6. Centre of Excellence for Food- and Vector-borne Zoonoses, Institute for Medical Research, University of Belgrade, Belgrade, Serbia

7. Department of Parasitology, National Public Health Institute, Budapest, Hungary

8. Institute of Microbiology and Immunology, Faculty of Medicine, University of Ljubljana, Ljubljana, Slovenia

9. National Food Chain Safety Office, Veterinary Diagnostic Directorate, Budapest, Hungary

10. Banat's University of Agricultural Sciences and Veterinary Medicine 'King Michael I of Romania' from Timişoara, Faculty of Veterinary Medicine, Department of Animal Production and Veterinary Public Health, Timişoara, Romania

11. University of Sarajevo, Veterinary Faculty, Department of Parasitology and Invasive Diseases of Animals, Sarajevo, Bosnia and Herzegovina

12. Department for Parasitology and Parasitic Diseases with Clinic, Faculty of Veterinary Medicine, University of Zagreb, Zagreb, Croatia

13. Department of Microbiology, Public Health Institute of Istrian Region, Pula, Croatia

14. Department of Parasitology, National Veterinary Research Institute, Putawy, Poland

15. Institute of Food Safety, Animal Health and Environment - 'BIOR', Riga, Latvia

16. Faculty of Veterinary Medicine, Latvia University of Agriculture, Jelgava, Latvia

17. Institute of Parasitology, Biology Centre of the Czech Academy of Sciences, České Budějovice, Czech Republic

18. Faculty of Agriculture, University of South Bohemia in České Budějovice, České Budějovice, Czech Republic

19. Health Institute in Ústí nad Labem, Prague, Czech Republic

20. State Key Laboratory for Plateau Ecology and Agriculture, Centre for Biomedicine and Infectious Diseases Qinghai University, Xining, China

21. Medical School, University of Cologne, Cologne, Germany

Correspondence: Judit Plutzer (plujud@yahoo.com)

Citation style for this article:

Plutzer Judit, Lassen Brian, Jokelainen Pikka, Djurković-Djaković Olgica, Kucsera István, Dorbek-Kolin Elisabeth, Šoba Barbara, Sréter Tamás, Imre Kálmán, Omeragić Jasmin, Nikolić Aleksandra, Bobić Branko, Živičnjak Tatjana, Lučinger Snježana, Stefanović Lorena Lazarić, Kučinar Jasmina, Sroka Jacek, Deksne Gunita, Keidāne Dace, Kváč Martin, Hůzová Zuzana, Karanis Panagiotis. Review of Cryptosporidium and Giardia in the eastern part of Europe, 2016. Euro Surveill. 2018;23(4):pii=16-00825. https://doi.org/10.2807/1560-7917.ES.2018.23.4.16-00825

Introduction: This paper reviews the current knowledge and understanding of Cryptosporidium spp. an d Giardia spp. in humans, animals and the environment in 10 countries in the eastern part of Europe: Bosnia and Herzegovina, Croatia, Czech Republic, Estonia, Hungary, Latvia, Poland, Romania, Serbia and Slovenia. Methods: Published scientific papers and conference proceedings from the international and local literature, official national health service reports, national databases and doctoral theses in local languages were reviewed to provide an extensive overview on the epidemiology, diagnostics and research on these pathogens, as well as analyse knowledge gaps and areas for further research. Results: Cryptosporidium spp. and Giardia spp. were found to be common in eastern Europe, but the results from different countries are difficult to compare because of variations in reporting practices and detection methodologies used. Conclusion: Upgrading and making the diagnosis/detection procedures more uniform is recommended throughout the region. Public health authorities should actively work towards increasing reporting and standardising reporting practices as these prerequisites for the reported data to be valid and therefore necessary for appropriate control plans.

\section{Introduction}

Cryptosporidium spp. and Giardia spp. have been ranked as the sixth and 11th most important foodborne parasites globally, respectively [1]. Both parasites are shed in the faeces of infected hosts and can infect new hosts via faecal-contaminated soil, water, feed and food [2]. Several Cryptosporidium species are clearly zoonotic, including $C$. parvum, while human giardiasis is caused by two genetically different groups of $G$. intestinalis, referred to as assemblages $A$ and $B$, which can infect other mammalian hosts and thus have a zoonotic potential [3]. Control of pathogens 
Countries invited to review data on Cryptosporidium spp. and Giardia spp. from a One Health perspective, 2016

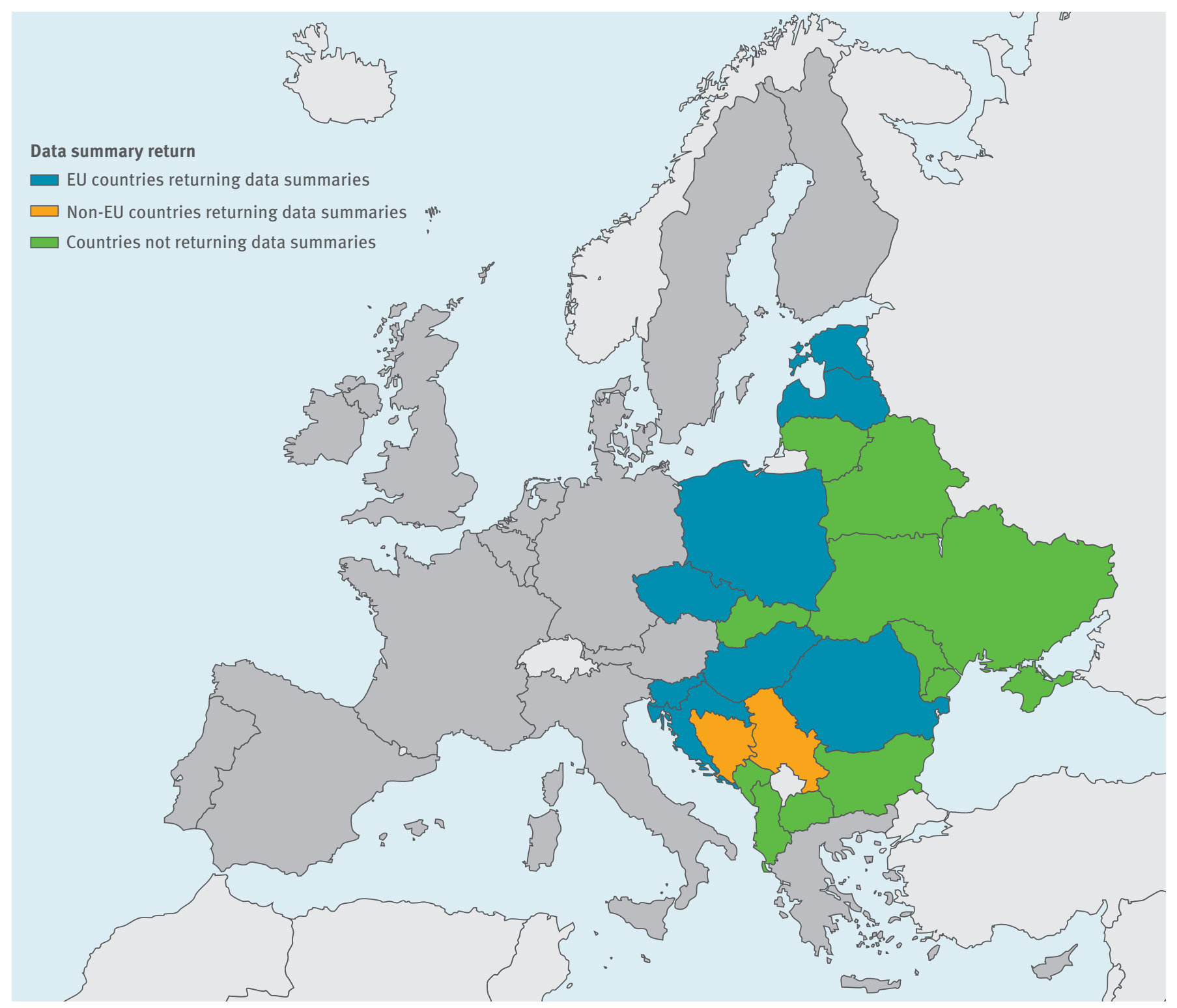

EU: European Union.

Administrative boundaries: EuroGeographics, UN-FAO.

that can be transmitted among humans, animals and the environment is best achieved with the One Health approach.

Among food-borne diseases, cryptosporidiosis and giardiasis cause a considerable burden at the global level [4], but the burden at regional and national levels is largely unknown $[1,5]$. Moreover, the current estimates of the burden caused by zoonotic pathogens only include a part of the potential impacts and true costs. In a One Health context, the estimates of disease burden would address that in humans and that in animals, including reduced human and animal health, economic losses, environmental contamination and the impact on biodiversity.
The most common clinical presentation of human cryptosporidiosis is profuse watery diarrhoea with abdominal pain, low-grade fever, nausea, vomiting and weight loss. It is often asymptomatic, mild or selflimiting in immunocompetent individuals and serious, even fatal in immunosuppressed individuals, such as HIV-infected persons [6,7]. A Cryptosporidium spp. infection can also be fatal in several mammalian animals and chronic in reptiles [8].

The clinical features of acute giardiasis in humans are similar to cryptosporidiosis, and include severe diarrhoea, abdominal cramps, nausea and weight loss. These symptoms may persist for a few weeks or evolve 


\section{TABLE 1}

Number of laboratory-confirmed Cryptosporidium spp. and Giardia intestinalis cases ${ }^{\mathrm{a}}$ and reported incidence per 100,000 inhabitants ${ }^{\mathrm{b}}, 10$ countries in the eastern part of Europe, 2016

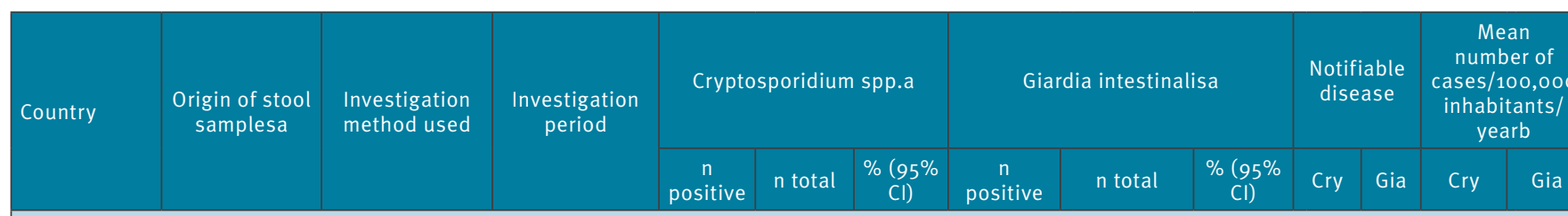

European Union countries

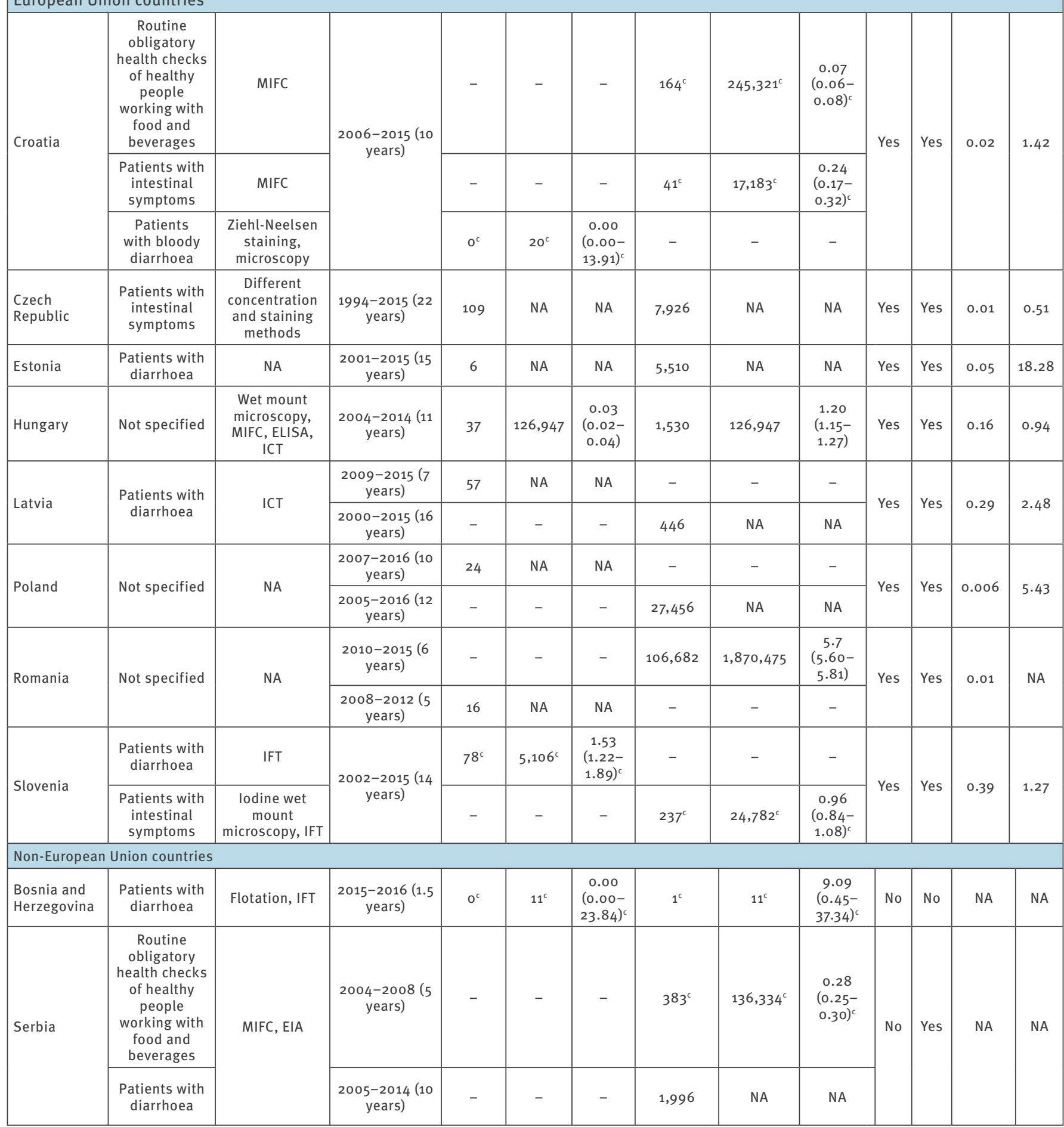

-: not applicable; $\mathrm{Cl}$ : confidence interval; Cry: cryptosporidiosis; ECDC: European Centre for Disease Prevention and Control; EIA: enzyme immunoassay; Gia: giardiasis; ICT: immunochromatographic test; IFT: immunoflourescence test; MIFC: merthiolate-iodine-formaldehyde concentration; NA: not available.

a Laboratory-confirmed cases as reported by national public health laboratories.

${ }^{b}$ Mean notification rate extracted from 2007-2016 data in the ECDC Surveillance Atlas of Infectious Diseases [11].

' Regional data, does not represent the whole country. Croatia: data from Istria region; Slovenia: data from various regions; Bosnia and Herzegovina: data from Canton of Sarajevo; Serbia: data from region of Nis. 
into a chronic reoccurring disease. The infection may be asymptomatic or a subclinical course [9]. Giardia spp. infection in cattle, goats and sheep can cause nutrient malabsorption that can consequently result in a reduction of weight gain. Although mortality due to giardiasis is uncommon, fatal giardiasis has been reported in chinchillas and birds [10].

Microscopic examination of stool specimens remains the cornerstone of diagnostic testing for these parasites, although molecular methods and immunological assays can effectively replace microscopic approaches. Microscopy is cheap, but requires a skilled parasitologist and the diagnostic yield is dependent on proper stool collection. The treatment options for both include antiparasitic drugs and fluid therapy.

According to 2015 data on food-borne and waterborne diseases and zoonoses in the European Centre for Disease Prevention and Control's (ECDC) Surveillance Atlas of Infectious Diseases, 0.68\% (73/10,805; 95\% confidence interval (Cl): $0.53-0.84)$ of confirmed cryptosporidiosis cases and $26.71 \% \quad(4,739 / 17,740$; 95\% Cl: 26.1-27.4) of confirmed giardiasis cases were reported by 10 countries of the European Union (EU) that are mostly in the eastern part of Europe: Bulgaria, Czech Republic, Estonia, Hungary, Latvia, Lithuania, Poland, Romania, Slovakia and Slovenia [11]. These countries make up $20 \%$ of the EU population [12]. Considering that Cryptosporidium spp. and Giardia spp. are transmitted via similar pathways, and that one fourth of all giardiasis cases notified in the EU were from these 10 countries, the low proportion of cryptosporidiosis cases suggests underreporting. In general, relatively little is known about the presence of Cryptosporidium spp. and Giardia spp. in the eastern part of Europe despite their public health relevance. This review aimed to assess the significance of Cryptosporidium spp. and Giardia spp. infections in humans and animals, as well as their occurrence in the environment based on (locally) available data. While the data are challenging to compare, they provide an overall picture of the situation and main knowledge gaps.

\section{Methods}

For the purpose of this analysis, we considered the following 19 countries to comprise eastern Europe: Estonia, Latvia, Lithuania, Czech Republic, Hungary, Poland, Slovakia, Slovenia, Albania, Bulgaria, Bosnia and Herzegovina, the former Yugoslav Republic of Macedonia, Montenegro, Croatia, Serbia, Belarus, Moldova, Ukraine and Romania (Figure).

Experts including public health specialists, epidemiologists, parasitologists and other laboratory scientists working on human, animal and environmental samples from the 19 countries were invited in January 2016 to collect and review the data available for their country from a One Health perspective. Experts from 11 of 19 countries responded; those from 10 countries (Bosnia and Herzegovina, Croatia, Czech Republic, Estonia, Hungary, Latvia, Poland, Romania, Serbia, Slovenia) sent summary reviews, while those from the former Yugoslav Republic of Macedonia responded that no data were available. Eight countries (Albania, Belarus, Bulgaria, Lithuania, Moldova, Montenegro, Slovakia and Ukraine) offered no data for the review (Figure).

The contacted experts from each country gathered data from sources including national official health service reports, national databases, and international and national publications. These experts also conducted a PubMed (Medline) literature search between April and October 2016 to identify internationally published data while Google databases, using defined qualifiers for $G$ iardia, Cryptosporidium and geographic location (e.g. Hungary), were used to identify data from grey literature. In addition, searches in local databases identified doctoral theses, journals and other publications available in the main local languages (Bosnian, Croatian, Czech, Estonian, Hungarian, Latvian, Polish, Romanian, Serbian, Slovenian) in the participating countries. Data on epidemiology, diagnostics and research of the two parasites in humans, in animals, and in the environment were extracted.

Based on the extracted data, the $95 \%$ confidence intervals $(\mathrm{Cl})$ of prevalence and the two-tailed $\mathrm{p}$ values of two-by-two table comparisons were calculated using the mid-P exact method with the OpenEpi v.3.01 programme [13]. If detailed data were not given, we report the count, percentage and $\mathrm{Cl}$ as presented in the original publication. Data in this paper are presented on a country-by-country basis in alphabethical order.

\section{Results}

\section{Bosnia and Herzegovina}

Humans

Cryptosporidium spp. and Giardia intestinalis data available from routine human investigations are shown in Table 1. Investigations are performed by the Laboratory of Parasitology, Veterinary Faculty at the University of Sarajevo. Reporting on these parasites is not mandatory in Bosnia and Herzegovina.

\section{Animals}

At present, research on parasites is rare in Bosnia and Herzegovina and investigations have mainly focused on the presence of helminths. Some types of protozoa, such as the species of the genus Cryptosporidium and Giardia, were described as additional findings. Hodžić et al. provided the first written information about the occurrence and distribution of Cryptosporidium spp. and Giardia spp. in Bosnia and Herzegovina [14]. They investigated 123 faecal samples from red foxes (Vulpes vulpes) during the hunting seasons between January 2011 and March 2012. The samples were analysed for the presence of Cryptosporidium spp. oocysts and G. intestinalis cysts using sucrose flotation concentration and 


\section{TABLE 2}

Prevalence of Cryptosporidium species and genotypes in domestic animals including pets and wild animals using RFLP or/ and sequencing of PCR products, Czech Republic, 2003-2016

\begin{tabular}{|c|c|c|c|c|c|c|c|}
\hline Animals & n positive & $\mathrm{n}$ total & $\%(95 \% \mathrm{Cl})$ & Cryptosporidium spp. & Cryptosporidiumsubtypes & $\begin{array}{c}\text { Method (and } \\
\text { sequenced molecular } \\
\text { markers) }\end{array}$ & Reference \\
\hline \multicolumn{8}{|l|}{ Domestic } \\
\hline \multirow{3}{*}{ Cattle } & $11^{\mathrm{a}}$ & NA & NA & C. parvum, C. andersoni & NA & $\begin{array}{c}\text { PCR (SSU rRNA, } \\
\text { HSP70) }\end{array}$ & [122] \\
\hline & 44 & 995 & $4.42(3.27-5.84)$ & $\begin{array}{c}\text { C. andersoni, C. parvum, C. } \\
\text { bovis }\end{array}$ & $\mathrm{IlaA}_{15} \mathrm{G}_{2} \mathrm{R}_{1}$ & $\begin{array}{l}\text { PCR (SSU rRNA, } \\
\text { gp6o) }\end{array}$ & [123] \\
\hline & 56 & 309 & $18.12(4.12-22.72)$ & $\begin{array}{c}\text { C. andersoni, C. parvum, C. } \\
\text { bovis }\end{array}$ & $\begin{array}{l}\text { IlaA16G1R1, IlaA22G1R1, } \\
\text { IlaA18G1R1, IlaA15G1R1 }\end{array}$ & $\begin{array}{l}\text { PCR (SSU rRNA, } \\
\text { gp6o) }\end{array}$ & [119] \\
\hline \multirow{5}{*}{ Pigs } & $1^{\mathrm{a}}$ & NA & NA & C. suis & NA & $\begin{array}{c}\text { PCR (SSU rRNA, } \\
\text { HSP70) }\end{array}$ & {$[122]$} \\
\hline & 34 & 123 & $27.64(20.29-36.04)$ & $\begin{array}{l}\text { C. suis, C. scrofarum, C. } \\
\text { parvum }\end{array}$ & IlaA16G1R1 & $\begin{array}{l}\text { PCR (SSU rRNA, } \\
\text { gp6o) }\end{array}$ & {$[124]$} \\
\hline & 69 & 413 & $16.71(13.34-20.54)$ & $\begin{array}{l}\text { C. suis, C. scrofarum, } C . \\
\text { muris }\end{array}$ & NA & RFLP (SSU rRNA) & {$[125]$} \\
\hline & 177 & 477 & $37.11(32.86-41.51)$ & C. suis, C. scrofarum & NA & RFLP (SSU rRNA) & [126] \\
\hline & 353 & 1620 & $20.79(7.95-16.67)$ & $\begin{array}{l}\text { C. suis, C. scrofarum, C. } \\
\text { parvum, C. muris }\end{array}$ & NA & RFLP (SSU rRNA) & {$[127]$} \\
\hline Horses & 12 & 352 & $3.41(1.86-5.72)$ & $\begin{array}{c}\text { C. muris, horse } \\
\text { genotype, C. parvum, C. } \\
\text { tyzzeri }\end{array}$ & $\begin{array}{c}\mathrm{IVaA}_{15} \mathrm{G}_{4}, \mathrm{IlaA}_{15} \mathrm{G}_{2} \mathrm{R} 1 \\
\mathrm{IXbA22R9}\end{array}$ & $\begin{array}{l}\text { PCR (SSU rRNA, } \\
\text { gp6o) }\end{array}$ & [128] \\
\hline Cat & $1^{a}$ & NA & NA & C. felis & NA & $\begin{array}{c}\text { PCR (SSU rRNA, } \\
\text { HSP70) }\end{array}$ & [122] \\
\hline $\begin{array}{l}\text { Red-crowned } \\
\text { parakeets }\end{array}$ & $4^{\mathrm{a}}$ & NA & NA & C. avium & NA & $\begin{array}{l}\text { PCR (SSU rRNA, } \\
\text { HSP70, actin) }\end{array}$ & [129] \\
\hline Tortoises & 46 & 387 & $12.66(8.66-15.11)$ & $\begin{array}{c}\text { C. testudinis, } C \text {. } \\
\text { ducismarci, tortoise } \\
\text { genotype III }\end{array}$ & NA & $\begin{array}{l}\text { PCR (SSU rRNA, } \\
\text { COWP, actin) }\end{array}$ & [42] \\
\hline \multicolumn{8}{|l|}{ Wild } \\
\hline \multirow{2}{*}{ Wild boars } & 32 & 193 & $16.58(11.83-22.33)$ & C. suis, C. scrofarum & NA & RFLP (SSU rRNA) & [130] \\
\hline & 61 & 460 & $13.26(10.39-16.60)$ & C. suis, C. scrofarum & NA & RFLP (SSU rRNA) & [131] \\
\hline Giraffe & $1^{\mathrm{a}}$ & NA & NA & C. muris & NA & PCR (SSU rRNA) & [132] \\
\hline \multirow{2}{*}{ Ungulates } & $6^{\mathrm{a}}$ & NA & NA & $\begin{array}{c}\text { C. ubiquitum, C parvum, C. } \\
\text { andersoni }\end{array}$ & NA & $\begin{array}{c}\text { PCR (SSU rRNA, } \\
\text { HSP70) }\end{array}$ & [122] \\
\hline & 10 & 269 & $3.72(1.90-6.52)$ & $\begin{array}{c}\text { C. ubiquitum, C. muris, } \\
\text { deer genotype }\end{array}$ & XIId & $\begin{array}{l}\text { PCR (SSU rRNA, } \\
\text { gp6o) }\end{array}$ & [133] \\
\hline \multirow{3}{*}{ Birds } & $17^{\mathrm{a}}$ & NA & NA & C. meleagridis, C. baileyi & NA & $\begin{array}{c}\text { PCR (SSU rRNA, } \\
\text { HSP70) }\end{array}$ & [122] \\
\hline & $663^{b}$ & NA & NA & C. baileyi, C. meleagridis & NA & PCR (HSP70) & {$[134]$} \\
\hline & $85^{\mathrm{b}}$ & NA & NA & C. baileyi, C. meleagridis & IIleA16G2R1C & $\begin{array}{l}\text { PCR (SSU rRNA, } \\
\text { HSP7o, gp6o) }\end{array}$ & {$[135]$} \\
\hline Mouse & $14^{\mathrm{a}}$ & NA & NA & C. tyzzeri & IXaA6, IXaA8, IXbA6, & $\begin{array}{l}\text { PCR (SSU rRNA, } \\
\text { gp6o, actin, COWP, } \\
\text { TRAP-C1) }\end{array}$ & [136] \\
\hline Rodents & $7^{a}$ & NA & NA & C. muris, C. andersoni & NA & $\begin{array}{c}\text { PCR (SSU rRNA, } \\
\text { HSP70) }\end{array}$ & {$[122]$} \\
\hline $\begin{array}{l}\text { Siberian } \\
\text { chipmunks }\end{array}$ & 1 & 1 & $100(5-100)$ & C. muris & NA & PCR (SSU rRNA) & {$[137]$} \\
\hline Reptiles & $10^{\mathrm{a}}$ & NA & NA & $\begin{array}{l}\text { C. serpentis, C. varanii, } \\
\text { C. muris }\end{array}$ & NA & $\begin{array}{c}\text { PCR (SSU rRNA, } \\
\text { HSP70) }\end{array}$ & [122] \\
\hline Rabbits & 2 & 2 & $100(22.36-100)$ & C. cuniculus & NA & $\begin{array}{c}\text { PCR (SSU rRNA, } \\
\text { HSP70) }\end{array}$ & [122] \\
\hline Hedgehogs & 12 & 15 & $80(54.65-94.65)$ & C. parvum, C. erinacei & NA & $\begin{array}{l}\text { PCR (SSU rRNA, } \\
\text { gp6o) }\end{array}$ & [138] \\
\hline Bats & 3 & 263 & $1.14(0.29-3.07)$ & C. parvum, bat genotype III & NA & PCR (SSU rRNA) & [139] \\
\hline
\end{tabular}

$\mathrm{Cl}$ : confidence interval; COWP: Cryptosporidium oocyst wall protein; gp6o: 60 kilodalton glycoprotein; HSP70: 70 kilodalton heat shock protein; NA: not available; RFLP: restriction fragment length polymorphism; SSU rRNA: small subunit ribosomal ribonucleic acid; TRAP-C1: thrombospondin related adhesive proteins.

a Selected samples.

b Pooled samples. 
TABLE 3

Prevalence of Giardia spp. in domestic animals and wild ungulates, Czech Republic, 1993-2007

\begin{tabular}{|c|c|c|c|c|c|}
\hline Animals & Category & n positive & $\mathrm{n}$ total & $\%(95 \% \mathrm{Cl})$ & Reference \\
\hline \multirow{4}{*}{ Dogs } & Shelter & 26 & 243 & $10.70(7.26-15.07)$ & \multirow{2}{*}{ [140] } \\
\hline & Private, purebred & 2 & 83 & $2.41(0.41-7.73)$ & \\
\hline & Private, purebred, city & 37 & 3870 & $0.96(0.68-1.30)$ & \multirow{2}{*}{ [141] } \\
\hline & Private purebred, rural area & 12 & 540 & $2.22(1.21-3.75)$ & \\
\hline Sheep & Lamb $0.5-4$ months & 28 & 167 & $16.77(11.67-23.01)$ & \multirow{2}{*}{ [142] } \\
\hline Goats & Kids $0.5-4$ months & 19 & 26 & $73.08(53.86-87.39)$ & \\
\hline Horses & Not specified & 18 & 360 & $5.00(3.08-7.64)$ & [143] \\
\hline Roe deer & Calf 7-8 months & 1 & 3 & $33.33(1.67-86.80)$ & [144] \\
\hline
\end{tabular}

$\mathrm{Cl}$ : confidence interval.

immunofluorescence test (IFT). Cryptosporidium spp. and $G$. intestinalis were detected in $3.25 \%(4 / 123 ; 95 \%$ $\mathrm{Cl}: 1.04-7.66)$ and $7.32 \%(9 / 123 ; 95 \% \mathrm{Cl}: 3.63-13.00)$ of the samples, respectively. Co-infection with both parasites was not found. Dog faeces investigations using sucrose flotation concentration and IFT showed 5.00-6.90\% positivity for Cryptosporidium spp. and $6.60-11.84 \%$ for Giardia spp. with no age-dependent differences [15,16]. However, a more recent study reported a higher prevalence (100\%) of Giardia spp. in dogs $\leq 6$ months of age compared with older dogs $(p<0.001)[17]$.

\section{Croatia}

\section{Humans}

There has been an obligation for clinicians to report both parasites since 2012. However, the only data available for this review for the years 2006 to 2015 were those obtained from the Department of Microbiology, Public Health Institute of the Istrian Region, which serves an area of ca 200,000 inhabitants. Of the stool samples examined for Giardia cysts, 245,321 came from the obligatory occupational health checks of healthy people working with food and beverages while 17,183 were sent by clinicians for diagnostic purposes. Routine methods are used, including merthiolateiodine-formaldehyde concentration (MIFC), to concentrate protozoa and worm eggs from faecal samples. For patients with bloody diarrhoea, Ziehl-Neelsen staining and microscopy of bloody stool are used to determine the presence of Cryptosporidium spp. The presence of $G$. intestinalis and Cryptosporidium spp. in human stool samples in the region of Istria is presented in Table 1.

\section{Animals}

During the 9-year period from 2007 to 2015, a total of 5,387 stool samples from sick, but not necessarily diarrhoeic, canines and felines were examined for parasites at the Department for Parasitology and Parasitic Diseases with Clinic, Faculty of Veterinary Medicine, University of Zagreb. The canine and feline faecal samples were investigated by MERIFLUOR IFT
(Meridian Bioscience, Inc. Cincinnati, United States (US)) after concentration by centrifugation-flotation with sucrose. Cryptosporidium spp. was present in $0.31 \%(17 / 5,387 ; 95 \% \mathrm{Cl}: 0.19-0.49)$ and G. intestinalis in $25.88 \%(1,394 / 5,387 ; 95 \% \mathrm{Cl}: 24.72-27.06)$ of canine and feline faecal samples.

\section{Czech Republic}

\section{Humans}

In the years 1975 to 1982 , a total of 1,750 immunocompetent persons, mostly employed by agricultural enterprises, were examined for the presence of gastrointestinal parasites [18]. Of these, none were positive for Cryptosporidiumspp., but 0.80\% (14/1,750; $95 \%$ $\mathrm{Cl}$ : $0.48-1.38)$ were positive for $G$. intestinalis using Breza's, MIFC and Army Medical Service III concentration techniques and direct microscopy [19,20]. The first human cryptosporidiosis case in the Czech Republic was recorded by Ditrich et al. in an immunodeficient patient in 1991 [21]. The authors identified the Cryptosporidium isolate from that case as $C$. baileyi, but the identification was made without molecular analysis and therefore cannot be considered accurate. Based on the data from National Reference Laboratory for the Diagnostics of Intestinal Parasites, Department of Parasitology, Mycology and Mycobacteriology, Prague Institute of Public Health in Ústí nad Labem, 109 findings of Cryptosporidium spp. and 7,926 findings of $G$. intestinalis have been reported from 1994 to 2015 across the Czech Republic (Table 1). Of these, 104 (95.41\%; 95\% Cl: 90.13-98.30) findings of Cryptosporidium spp. and 5,607 (70.74\%; $95 \% \mathrm{Cl}: 69.73-71.74)$ findings of Giardia spp. were autochthonous, while the remaining Cryptosporidiu $m$ and Giardia cases represent imported infections. Few Cryptosporidiumgenotyping/subtyping results are available. In a study mapping the occurrence of various diarrhoeal pathogens in children hospitalised with diarrhoea between 1992 and 1996, 11.32\% (12/106; 95\% Cl: 6.28-18.45) were positive for Cryptosporidium based on aniline-methyl-violet staining of stool smears [22,23]. Nine of 106 Cryptosporidium-positive samples originated from immunocompetent children 5 
TABLE 4

Prevalence of Cryptosporidium spp. in ruminants using Sheather's sucrose flotation and direct microscopy, Hungary, 2005-2015

\begin{tabular}{|c|c|c|c|c|}
\hline Animal & Age category & $\mathrm{n}$ positive & $\mathrm{n}$ total & $\%(95 \% \mathrm{Cl})$ \\
\hline \multirow{4}{*}{ Cattle } & Adult & 63 & 7,205 & $0.87(0.68-1.11)$ \\
\cline { 2 - 5 } & Post-weaned & 18 & 466 & $3.86(2.38-5.92)$ \\
\cline { 2 - 5 } & Pre-weaned & 97 & 286 & $33.91(28.60-39.55)$ \\
\hline \multirow{4}{*}{ Sheep } & Adult & 1 & 517 & $0.19(0.01-0.95)$ \\
\cline { 2 - 5 } & Post-weaned & 3 & 175 & $1.71(0.44-4.60)$ \\
\cline { 2 - 5 } & Pre-weaned & 5 & 26 & $19.23(7.41-37.60)$ \\
\hline \multirow{3}{*}{ Goat } & Adult & 0 & 117 & $0.00(0.00-2.53)$ \\
\cline { 2 - 5 } & Post-weaned & 1 & 78 & $1.28(0.06-6.94)$ \\
\cline { 2 - 5 } & Pre-weaned & 2 & 7 & $28.57(5.10-66.98)$ \\
\hline
\end{tabular}

$\mathrm{Cl}$ : confidence interval.

a Based on the database of National Food Chain Safety Office, Veterinary Diagnostic Directorate, Budapest, Hungary.

months to 8 years of age and were subsequently genotyped by Hajdušek et al.; eight cases of $C$. parvum and one case of $C$. hominis were reported based on PCR amplification of partial sequences of the small subunit ribosomal ribonucleic acid (SSU rRNA) and Cryptosporidium oocyst wall protein (COWP) genes [24]. In diarrhoeal stool samples $(n=457)$ from 203 immunocompetent patients under 69 years of age with suspected cryptosporidiosis, five children were positive for $C$. parvum, one child was positive for $C$. hominis and one adult was positive for $C$. scrofarum based on PCR amplification of the SSU rRNA gene [25]. Additionally, two unusual cases of cryptosporidiosis caused by $C$. erinacei and a mixed infection of $C$. parvum and $C$. tyzzeri were reported by Rašková et al. and Kváč et al. [26,27].

Seroprevalence data showed that $66.83 \%(133 / 199$; 95\% Cl: 60.07-73.11) and 71.86\% (143/199; 95\% Cl: 65.31-77.78) of the inhabitants of the Czech Republic have antibodies and a positive response to the 15/17$\mathrm{kDa}$ and 27-kDa Cryptosporidium antigen groups, respectively [28]. Pospíšilová et al. showed high titres of anti-Cryptosporidiumantibodies in $10.71 \%$ of AIDS patients (15/140; 95\% Cl: 6.36-16.68) [29].

Animals

More than 60 studies have reported the presence of Cryptosporidium in animals, with many including data on genotyping, host and age range, pathogenicity and host-pathogen relations. The studies also resulted in the description of C. avium, C. proliferans, C. scrofarum, C. fragile, C. erinacei and C. testudinis as novel species of the genus Cryptosporidium [30-46]. In the Czech Republic, Cryptosporidium spp. was first detected in 1979 in two 14-day old emergency slaughter bulls [47]. Until the beginning of the 21st century, Cryptosporidium spp. has been found in many animal hosts (cattle, goats, sheep, pigs, poultry, wild ungulates and rodents) using microscopic techniques (flotation in Sheather's sugar or Breza's solution, native preparation, aniline-carbol-methyl violet or Giemsa staining methods); however, most studies lacked genetic characterisation of the isolates [31,48-54]. In the past decade, molecular tools have been widely used to determine the species/genotype of Cryptosporidium present in cryptosporidiosis cases in domestic, wild and companion hosts (Table 2 ).

A few studies have reported on the presence of Giardia in dogs, domestic animals and wild ungulates (Table 3). Unfortunately, all studies were based on microscopic examination of samples using native preparation, flotation in Sheather's sugar or Breza's solution, or staining methods. As no genotyping tools were used and information on genetic assemblages is lacking.

Environment

Monitoring of Cryptosporidium oocysts and Giardia cysts in drinking water resources was published by Dolejš et al. in 1999 and 2000 [5558]. Drinking water sources in the Czech Republic have been found to contain between 0 and 32,140 Cryptosporidium spp. oocysts/100 L and between 0 and 485 Giardia spp. cysts/100 L based on IFT and microscopy. Hajdušek et al. used molecular tools to identify $C$. parvum in an open water reservoir in 2004. This isolate was recovered from $10,000 \mathrm{~L}$ of water using a Super Micro-Wynd $1 \mu \mathrm{m}$ filter (CUNO Inc., Meriden, US) [24].

\section{Estonia}

Humans

Cryptosporidiosis and giardiasis are notifiable diseases in Estonia. From 1991 until 2016, a total of 134 cases of cryptosporidiosis have been reported by the Health Board, of which only a few have been in the recent years (Table 1) [59,60]. For 1991 to 1992, the official Estonian reports mention 33 cryptosporidiosis cases (personal communication, J Epštein, February 2014). During the same years, stool samples of patients with intestinal diseases $(n=1,518)$ were examined at one hospital using an unspecified microscopy method and Cryptosporidium oocysts were found in $3.34 \%(49 / 1,469 ; 95 \% \mathrm{Cl}: 2.51-4.35)$ of the stools from patients with acute intestinal disease who were 0-14 years of age [61]. Since 1999, reports on cryptosporidiosis have originated from two of 15 counties, Harjumaa and Raplamaa, and since 2010, all the individuals diagnosed with cryptosporidiosis were children [59]. The official data thus do not appear to include known outbreaks occurring among veterinary students [62]. One such case was caused by the C. parvumsubtype IlaA16G1R1, and there was evidence of the infection having originated from calf faeces [62].

According to the number of cases reported to ECDC from 2007 to 2016, Estonia has the second highest rate of laboratory-confirmed giardiasis cases with a 
Prevalence of Cryptosporidium spp. and Giardia spp. in domestic animals including pets and wild animals using different methods Poland, 1997-2014

\begin{tabular}{|c|c|c|c|c|c|c|c|}
\hline Animals & $\begin{array}{c}n \\
\text { positive }\end{array}$ & $\begin{array}{c}n \\
\text { total }\end{array}$ & $\%(95 \% \mathrm{Cl})$ & Cryptosporidium spp. & $\begin{array}{c}\text { Giardia spp./G. } \\
\text { intestinalisassemblage }\end{array}$ & $\begin{array}{c}\text { Method (and } \\
\text { sequenced } \\
\text { molecular } \\
\text { markers) }\end{array}$ & Reference \\
\hline \multicolumn{8}{|l|}{ Domestic } \\
\hline \multirow{3}{*}{ Cattle } & 10 & 86 & $11.63(6.06-19.75)$ & $\mathrm{NE}$ & G. intestinalis/A, E & PCR ( $\beta$-giardin) & \multirow{2}{*}[145,146]{} \\
\hline & 16 & 86 & $18.60(11.42-27.87)$ & $\mathrm{NE}$ & Giardia spp. & IFT & \\
\hline & 119 & 700 & $17.00(14.35-19.92)$ & $\begin{array}{l}\text { C. bovis, C. parvum, C. } \\
\text { andersoni, C. ryanae }\end{array}$ & NE & $\begin{array}{l}\text { PCR (SSU rRNA, } \\
\text { COWP) }\end{array}$ & {$[147]$} \\
\hline \multirow{3}{*}{ Pigs } & 8 & 84 & $9.52(4.52-17.28)$ & $\mathrm{NE}$ & G. intestinalis / B, E & PCR ( $\beta$-giardin) & \multirow{2}{*}[145,146]{} \\
\hline & 25 & 84 & $29.76(20.73-40.17)$ & $\mathrm{NE}$ & Giardia spp. & IFT & \\
\hline & 46 & 166 & $27.71(21.31-34.89)$ & $\begin{array}{c}\text { C. scrofarum, C. suis, C. } \\
\text { parvum }\end{array}$ & NE & $\begin{array}{l}\text { PCR (SSU rRNA, } \\
\text { COWP) }\end{array}$ & [148] \\
\hline \multirow{3}{*}{ Horses } & 1 & 10 & $10(0.50-40.35)$ & $\mathrm{NE}$ & G. intestinalis / E & PCR ( $\beta$-giardin) & \multirow{2}{*}[145,146]{} \\
\hline & 1 & 10 & $10(0.50-40.35)$ & $\mathrm{NE}$ & Giardia spp. & IFT & \\
\hline & 20 & 564 & $3.55(2.24-5.33)$ & C. parvum & $\mathrm{NE}$ & EIA, IFT, FISH & [149] \\
\hline \multirow{3}{*}{ Sheep } & 18 & 81 & $22.22(14.17-32.23$ & $\mathrm{NE}$ & G. intestinalis / A, E & PCR ( $\beta$-giardin) & \multirow{2}{*}[145,146]{} \\
\hline & 17 & 81 & $20.99(13.16-30.86)$ & $\mathrm{NE}$ & Giardia spp. & IFT & \\
\hline & 16 & 159 & $10.06(6.07-15.50)$ & C. parvum & $\mathrm{NE}$ & Microscopy $^{\mathrm{a}}$ & \multirow{2}{*}[150]{} \\
\hline Goats & 0 & 46 & $0.00(0.00-6.31)$ & Cryptosporidium spp. & $\mathrm{NE}$ & Microscopy $^{\mathrm{a}}$ & \\
\hline Cats & 4 & 160 & $2.50(0.80-5.92)$ & $\mathrm{NE}$ & G. intestinalis/A, B & PCR (GDH) & [151] \\
\hline \multirow{7}{*}{ Dogs } & 3 & 60 & $5.00(1.29-13.00)$ & $\mathrm{NE}$ & G. intestinalis/A, E & PCR ( $\beta$-giardin) & \multirow{2}{*}[145,146]{} \\
\hline & 7 & 60 & $11.67(5.25-21.72)$ & $\mathrm{NE}$ & Giardia spp. & IFT & \\
\hline & 32 & 350 & $9.14(6.45-12.51)$ & $\mathrm{NE}$ & G. intestinalis/A, C, D & PCR (GDH) & \multirow{2}{*}{ [152] } \\
\hline & 18 & 350 & $5.14(3.28-7.28)$ & $\mathrm{NE}$ & G. intestinalis & Microscopy $^{\mathrm{a}}$ & \\
\hline & 2 & 148 & $1.35(0.23-4.39)$ & $\mathrm{NE}$ & G. intestinalis/C, D & PCR ( $\beta$-giardin) & [153] \\
\hline & 8 & 64 & $12.5(5.98-22.36)$ & Cryptosporidium spp. & $\mathrm{NE}$ & \multirow{2}{*}{ IFT } & \multirow{2}{*}[154]{} \\
\hline & 23 & 64 & $35.94(24.92-48.20)$ & $\mathrm{NE}$ & Giardia spp. & & \\
\hline \multirow{2}{*}{$\begin{array}{l}\text { Domestic } \\
\text { birds }\end{array}$} & 1 & 101 & $0.99(0.50-4.79)$ & $\mathrm{NE}$ & G. intestinalis & Microscopya ${ }^{a}$ FISH & \multirow[b]{2}{*}[155]{} \\
\hline & 0 & 101 & $0.00(0.00-2.92)$ & C. parvum & NE & $\begin{array}{c}\text { Microscopya }{ }^{\mathrm{a}} \text { EIA, } \\
\text { FISH }\end{array}$ & \\
\hline \multicolumn{8}{|l|}{ Wild } \\
\hline \multirow{4}{*}{ Wild boars } & 4 & 27 & $14.81(4.89-31.97)$ & $\mathrm{NE}$ & Giardia spp. & IFT & \multirow{2}{*}[145,146]{} \\
\hline & 11 & 27 & $40.74(23.62-59.76)$ & $\mathrm{NE}$ & G. intestinalis / B & PCR ( $\beta$-giardin) & \\
\hline & 0 & 5 & $0.00(0.00-45.07)$ & Cryptosporidium spp. & NE & $\begin{array}{l}\text { Microscopya, IFT, } \\
\text { PCR (COWP) }\end{array}$ & \multirow{2}{*}{ [156] } \\
\hline & 0 & 5 & $0.00(0.00-45.07)$ & $\mathrm{NE}$ & Giardia spp. & Microscopy ${ }^{\mathrm{a}}$, IFA & \\
\hline \multirow{2}{*}{ Foxes } & 0 & 21 & $0.00(0.00-13.29)$ & $\mathrm{NE}$ & G. intestinalis & PCR ( $\beta$-giardin) & \multirow{4}{*}[145,146]{} \\
\hline & 4 & 21 & $19.05(6.36-39.80)$ & $\mathrm{NE}$ & Giardia spp. & IFT & \\
\hline \multirow{5}{*}{ Red deer } & 5 & 28 & $17.86(6.85-35.24)$ & $\mathrm{NE}$ & G. intestinalis/B & PCR ( $\beta$-giardin) & \\
\hline & 0 & 28 & $0.00(0.00-10.15)$ & $\mathrm{NE}$ & Giardia spp. & IFT & \\
\hline & 14 & 52 & $26.92(16.22-40.14)$ & Cryptosporidium spp. & NE & $\begin{array}{l}\text { Microscopy }{ }^{\mathrm{a}} \text {, IFT, } \\
\text { PCR (COWP) }\end{array}$ & \multirow{2}{*}{ [156] } \\
\hline & 1 & 52 & $1.92(0.10-9.12)$ & $\mathrm{NE}$ & Giardia spp. & Microscopy ${ }^{\mathrm{a}}$, IFT & \\
\hline & 1 & 61 & $1.64(0.08-7.82)$ & $\mathrm{NE}$ & Giardia spp. & Microscopy ${ }^{\mathrm{a}}$ & [157] \\
\hline
\end{tabular}

COWP: Cryptosporidium oocyst wall protein; EIA: enzyme immunoassay; IFT: immunoflourescent test; FISH: fluorescent in situ hybridisation; GDH: glutamate dehydrogenase; NA: not available; NE: not examined; SSU rRNA: small subunit ribosomal ribonucleic acid.

a Examination of smears of faecal samples or samples after Sheather's flotation and after modified Ziehl-Neelsen or Lugol' iodine or iron hematoxylin staining, or Willis-Schlaf or McMaster methods.

${ }^{\mathrm{b}}$ Number of sequenced samples. 


\section{TABLE 5B}

Prevalence of Cryptosporidium spp. and Giardia spp. in domestic animals including pets and wild animals using different methods Poland, 1997-2014

\begin{tabular}{|c|c|c|c|c|c|c|c|}
\hline Animals & $\begin{array}{c}n \\
\text { positive }\end{array}$ & $\begin{array}{c}n \\
\text { total }\end{array}$ & $\%(95 \% \mathrm{Cl})$ & Cryptosporidium spp. & $\begin{array}{c}\text { Giardia spp./G. } \\
\text { intestinalisassemblage }\end{array}$ & $\begin{array}{l}\text { Method (and } \\
\text { sequenced } \\
\text { molecular } \\
\text { markers) }\end{array}$ & Reference \\
\hline \multirow{5}{*}{ Roe deer } & 11 & 48 & $22.92(12.68-36.33)$ & $\mathrm{NE}$ & G. intestinalis/B & PCR ( $\beta$-giardin) & \multirow{2}{*}[145,146]{} \\
\hline & 2 & 48 & $4.17(0.70-13.09)$ & $\mathrm{NE}$ & Giardia spp. & IFT & \\
\hline & 2 & 22 & $9.09(1.55-26.92)$ & Cryptosporidium spp. & $\mathrm{NE}$ & $\begin{array}{l}\text { Microscopy }^{\mathrm{a}}, \mathrm{IFT} \\
\text { PCR (COWP) }\end{array}$ & \multirow{2}{*}{ [156] } \\
\hline & 1 & 22 & $4.55(0.23-20.44)$ & $\mathrm{NE}$ & Giardia spp. & Microscopy ${ }^{\mathrm{a}}$, IFT & \\
\hline & 2 & 50 & $\begin{array}{l}4.00(2 / 50 ; \\
0.68-12.59)\end{array}$ & $\mathrm{NE}$ & Giardia spp. & \multirow{3}{*}{ Microscopy ${ }^{a}$} & \multirow{3}{*}{ [157] } \\
\hline $\begin{array}{l}\text { Fallow } \\
\text { deer }\end{array}$ & 0 & 65 & $\begin{array}{l}0.00(0 / 65 ; \\
0.00-4.50)\end{array}$ & NE & Giardia spp. & & \\
\hline \multirow{3}{*}{ Moose } & 0 & 5 & $\begin{array}{c}0.00(0 / 5 \\
0.00-45.07)\end{array}$ & NE & Giardia spp. & & \\
\hline & 4 & 23 & $\begin{array}{l}17.39(4 / 23 \\
5.78-36.80)\end{array}$ & NE & G. intestinalis & PCR ( $\beta$-giardin) & \multirow{4}{*}[145,146]{} \\
\hline & 0 & 23 & $\begin{array}{l}0.00(0 / 23 \\
0.00-12.21)\end{array}$ & NE & Giardia spp. & IFT & \\
\hline \multirow{3}{*}{ Wolves } & 2 & 7 & $28.57(5.10-66.98)$ & $\mathrm{NE}$ & G. intestinalis/D & PCR ( $\beta$-giardin) & \\
\hline & 2 & 7 & $28.57(5.10-66.98)$ & $\mathrm{NE}$ & Giardia spp. & IFT & \\
\hline & 5 & 14 & $35.71(14.44-62.40)$ & C. parvum, genotype 2 & NE & $\begin{array}{l}\text { Microscopy }{ }^{\mathrm{a}}, \mathrm{IFT}, \\
\text { PCR (COWP) }\end{array}$ & [156] \\
\hline \multirow{6}{*}{ Rodents } & $10^{\mathrm{b}}$ & 266 & \multirow{2}{*}{ NA } & $\mathrm{NE}$ & G. microti, G. muris & \multirow{2}{*}{ PCR (SSU rRNA) } & \multirow{2}{*}{ [158] } \\
\hline & $8^{\mathrm{b}}$ & 266 & & C. parvum, C. ubiquitum & $\mathrm{NE}$ & & \\
\hline & 41 & 114 & $35.9(27.74-45.54)$ & Cryptosporidium spp. & $\mathrm{NE}$ & \multirow{2}{*}{ IFT } & \multirow{2}{*}{ [159] } \\
\hline & 0 & 114 & $0.00(0.00-4.06)$ & $\mathrm{NE}$ & Giardia spp. & & \\
\hline & NA & NA & $28.1-62.3(\mathrm{NA})$ & Cryptosporidium spp. & $\mathrm{NE}$ & \multirow{2}{*}{ Microscopy ${ }^{\mathrm{a}}$, IFT } & \multirow{2}{*}[160]{} \\
\hline & NA & NA & $24.4-74.2$ (NA) & $\mathrm{NE}$ & Giardia spp. & & \\
\hline \multirow{2}{*}{$\begin{array}{l}\text { European } \\
\text { beaver }\end{array}$} & 7 & 22 & $31.82(15.11-53.05)$ & Cryptosporidium spp. & NE & $\begin{array}{l}\text { Microscopy }{ }^{\mathrm{a}}, \mathrm{IFT}, \\
\text { PCR (COWP) }\end{array}$ & \multirow{5}{*}{ [156] } \\
\hline & 1 & 22 & $4.55(0.23-20.44)$ & $\mathrm{NE}$ & Giardia spp. & Microscopya ${ }^{a}$, IFT & \\
\hline \multirow{2}{*}{$\begin{array}{l}\text { European } \\
\text { bison }\end{array}$} & 16 & 55 & $29.09(18.27-42.07)$ & Cryptosporidium spp. & NE & $\begin{array}{l}\text { Microscopya, IFT, } \\
\text { PCR (COWP) }\end{array}$ & \\
\hline & 4 & 55 & $7.27(2.35-16.62)$ & $\mathrm{NE}$ & Giardia spp. & Microscopya, IFT & \\
\hline \multirow{2}{*}{$\begin{array}{l}\text { Polish } \\
\text { Konik } \\
\text { (horse) }\end{array}$} & 0 & 10 & $0.00(0.00-25.89)$ & Cryptosporidium spp. & NE & $\begin{array}{c}\text { Microscopy }{ }^{\mathrm{a}} \text {, IFT, } \\
\text { PCR (COWP) } \\
\end{array}$ & \\
\hline & 1 & 44 & $2.27(0.11-10.70)$ & Cryptosporidium spp. & $\mathrm{NE}$ & Microscopy $^{\mathrm{a}}$ & [161] \\
\hline \multirow{2}{*}{$\begin{array}{l}\text { Birds } \\
\text { captive }\end{array}$} & 2 & 90 & $2.22 \%(0.37-7.15)$ & $\mathrm{NE}$ & G. intestinalis & Microscopya , FISH & \multirow[b]{2}{*}[155]{} \\
\hline & 1 & 90 & $1.11 \%(0.06-5.36)$ & C. parvum & $\mathrm{NE}$ & $\begin{array}{c}\text { Microscopy }{ }^{\mathrm{a}}, \mathrm{EIA}, \\
\text { FISH }\end{array}$ & \\
\hline
\end{tabular}

COWP: Cryptosporidium oocyst wall protein; EIA: enzyme immunoassay; IFT: immunofluorescent test; FISH: fluorescent in situ hybridisation; GDH: glutamate dehydrogenase; NA: not available; NE: not examined; SSU rRNA: small subunit ribosomal ribonucleic acid.

a Examination of smears of faecal samples or samples after Sheather's flotation and after modified Ziehl-Neelsen or Lugol' iodine or iron hematoxylin staining, or Willis-Schlaf or McMaster methods.

${ }^{b}$ Number of sequenced samples.

mean of 18.3 cases per 100,000 inhabitants per year (Table 1), which is three times higher than the EU mean for the same time period [11]. In particular, the reported incidence rate among children $0-4$ years of age in Estonia between 2007 to 2016 (152.22 individuals per 100,000 inhabitants) was 10 times higher than the rate in all reporting countries ( 15.45 individuals per 100,000 inhabitants) [11]. In a national health report of the Health Board, 46.84\% (549/1,172; 95\% Cl: 44.00-49.71) of individuals with reported giardiasis in 2010 to 2014 were children less than 5 years of age [59]. The same report reported that $5.12-17.51 \%$ of all patients with giardiasis were hospitalised and that $70.20-80.71 \%$ of the annually reported cases in 2010 to 2014 originated from one county, Harjumaa, where the capital Tallinn is located [59].

Animals

In 2013 to 2015 , 30.04\% (73/243; 95\% Cl: $24.53-36.03)$ of bovine faecal samples submitted to the veterinary and 
TABLE 6

Prevalence and identification of Cryptosporidium spp. subtypes and Giardia intestinalis assemblages in animals using nonmolecular and molecular methods, Romania, 2005-2016

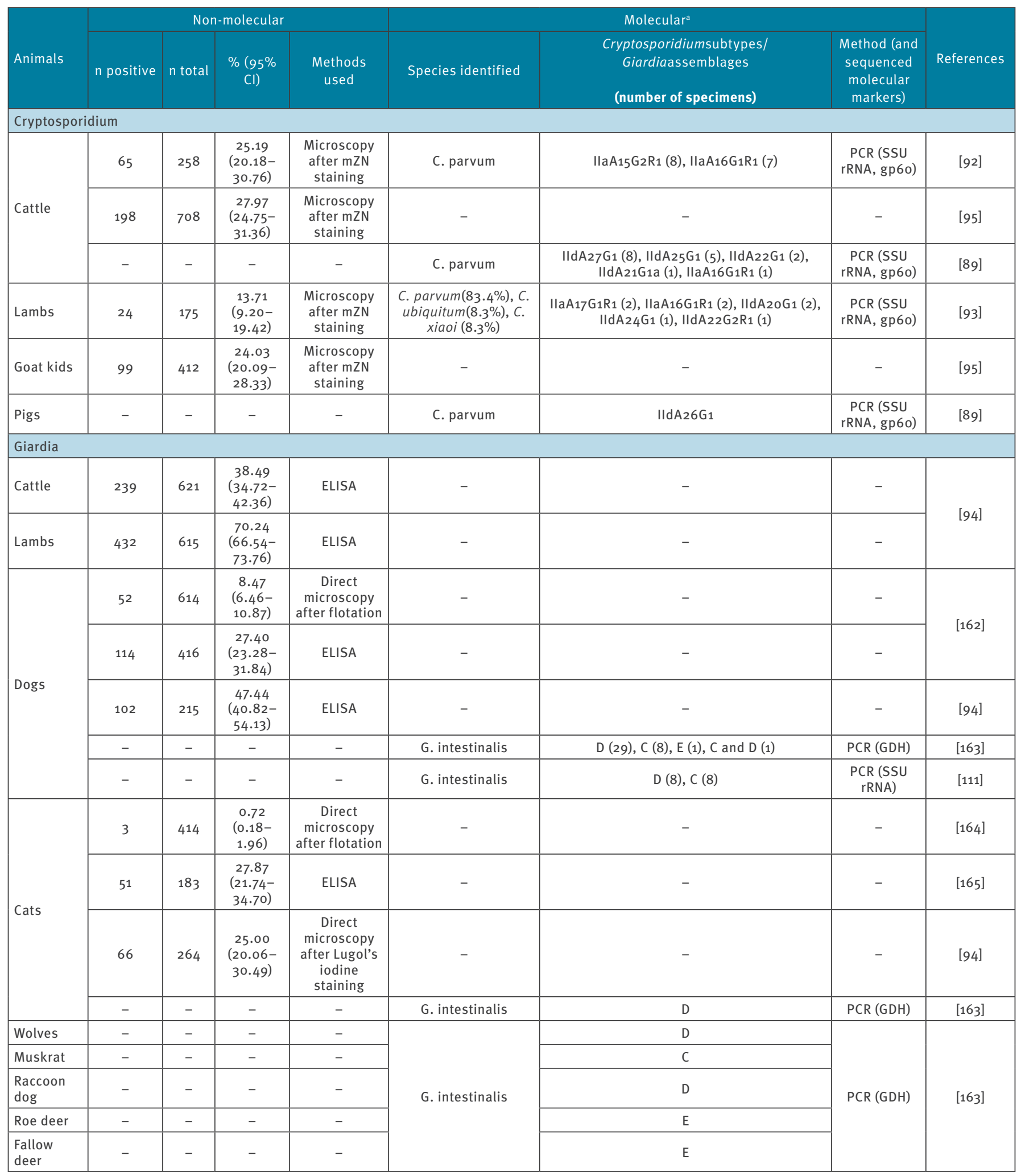

-: not applicable; $\mathrm{Cl}$ : confidence interval; ELISA: enzyme-linked immunosorbent assay; GDH: glutamate dehydrogenase; gp6o: 6o kilodalton glycoprotein; mZN: modified Ziehl-Neelsen; SSUrRNA: small subunit ribosomal ribonucleic acid.

a For molecular studies microscopically positive samples have been used. 
Prevalence of Cryptosporidium spp. and Giardia intestinalis and genotypes in animals using microscopy and PCR, Serbia, 2002-2015

\begin{tabular}{|c|c|c|c|c|c|c|}
\hline Animals & $\begin{array}{l}\mathrm{n} \\
\text { positive }\end{array}$ & $\begin{array}{l}\mathrm{n} \\
\text { total }\end{array}$ & $\%(95 \% \mathrm{Cl})$ & $\begin{array}{l}\text { Cryptosporidium subtypes/Giardiaassemblages } \\
\text { (number of specimens) }\end{array}$ & $\begin{array}{l}\text { Method (and } \\
\text { sequenced } \\
\text { molecular } \\
\text { markers) }\end{array}$ & References \\
\hline \multicolumn{7}{|c|}{ Cryptosporidium } \\
\hline \multirow{3}{*}{ Cattle } & 72 & 160 & $45.00(37.30-52.90)$ & NA & Microscopy & {$[107]$} \\
\hline & 62 & 103 & $60.19(50.52-69.30)$ & $\begin{array}{l}\text { C. parvum Ila (10), IlaA16G1R1b, IIaA18G1R1 Ila } \\
\text { A2oG1R1, IId (2), IId A18G1b, Ilj (6), IljA16R2, IljA17R2 }\end{array}$ & \begin{tabular}{|l|} 
PCR (SSU \\
rRNA, COWP) \\
\end{tabular} & [108] \\
\hline & 6 & 30 & $20.00(8.53-37.03)$ & NA & Microscopy & {$[166]$} \\
\hline \multirow{2}{*}{ Swine } & 89 & 260 & $34.23(28.65-40.16)$ & NA & Microscopy & [109] \\
\hline & 14 & 34 & $41.18(25.69-58.11)$ & NA & Microscopy & {$[166]$} \\
\hline \multirow{2}{*}{ Lambs } & 53 & 126 & $42.06(33.67-50.82)$ & NA & Microscopy & {$[167]$} \\
\hline & 12 & 25 & $48.00(29.19-67.25)$ & NA & Microscopy & {$[166]$} \\
\hline Goat & 28 & 88 & $31.82(22.74-42.08)$ & NA & Microscopy & {$[167]$} \\
\hline \multicolumn{7}{|l|}{ Giardia } \\
\hline \multirow[b]{2}{*}{ Dogs } & 22 & 151 & $14.57(9.60-20.89)$ & NA & Microscopy & [110] \\
\hline & 88 & 134 & $65.67(57.33-73.34)$ & G. intestinalis C (8), D (6) & $\begin{array}{l}\text { PCR (SSU } \\
\text { rRNA) }\end{array}$ & {$[111]$} \\
\hline \multirow{2}{*}{ Cats } & 18 & 81 & $22.22(14.17-32.23)$ & NA & Microscopy & [112] \\
\hline & 6 & 50 & $12.00(5.01-23.29)$ & NA & Microscopy & [113] \\
\hline
\end{tabular}

$\mathrm{Cl}$ : confidence interval; COWP: Cryptosporidium oocyst wall protein; EIA: enzyme immunoassay; SSU rRNA: small subunit ribosomal ribonucleic acid; NA: not available.

a Microscopy: examination of faecal sample smears or fecal samples after Sheather's flotation and modified Ziehl-Neelsen, Lugol' iodine or iron hematoxylin staining.

food laboratory were positive for Cryptosporidium spp. oocysts [63] and (personal communication, A Kärssin, February 2016). In 2010 to $2015,5.65 \%$ (7/124; 95\% $\mathrm{Cl}$ : $2.50-10.85)$ of canine faecal samples submitted to diagnostic examinations but none of the 50 feline samples tested positive for Cryptosporidium spp [63] and (personal communication, A Kärssin, February 2016). In a cross-sectional investigation, $30.28 \%$, (281/928; $95 \%$ Cl: $27.39-33.30 \%)$ of cattle tested positive for Cryptosporidium spp. oocysts using a modified Ziehl-Neelsen staining [64]. The same study found $84.44 \%$ (38/45; $95 \% \mathrm{Cl}: 71.64-92.93)$ of farms to have at least one animal shedding Cryptosporidium spp. oocysts at the time of the study. C. parvum and $C$. andersoni have been described in cattle less than 12 months of age [64]. The prevalence of shedding Cryptosporidium spp. oocysts was higher $(p<0.001)$ in animals older than 12 months of age compared with younger animals. However, evaluated with a semiquantitative scale, the younger animals appeared to shed in higher numbers [64]. Management practices that appeared to increase the magnitude of oocysts shedding included early removal of a calf from its mother [65]. Cryptosporidium spp. oocysts were detected with IFT in ovine faeces collected from $60.87 \%$ (56/92; $95 \% \mathrm{Cl}: 50.63-70.43$ ) of sheep herds on the islands of Hiiumaa, Vormsi and Saaremaa [66].

In 2010 to 2015 , Giardia cysts were detected in $27.08 \%$ (65/240; $95 \% \mathrm{Cl}: 21.75-32.97)$ of bovine faecal samples submitted for diagnostic investigations [63], (personal communication, A Kärssin, February 2016). In the same period, $5.65 \%(7 / 124 ; 95 \% \mathrm{Cl}: 2.50-10.85)$ of canine faecal samples and $14.00 \%$ (7/50; $95 \% \mathrm{Cl}: 6.33-25.74)$ of feline faecal samples were positive for Giardia cysts [64], (personal communication, A Kärssin, February 2016). Giardia shedding was detected with IFT in ovine faeces collected from in 69.57\% (64/92; 95\% Cl: 59.6178.31) of sheep herds on the islands of Hiiumaa, Vormsi and Saaremaa [66].

\section{Hungary}

\section{Humans}

Stool samples for both Cryptosporidium spp. oocysts and Giardia spp. cysts are routinely tested at the Department of Parasitology, National Center for Epidemiology and Regional Parasitological Laboratories in Budapest, Hungary using microscopic examination of the wet mount (saline and iodine) preparation, MIFC technique for concentration of the protozoan cysts, ELISA/immunochromatographic test (ICT) antigen detection and/or Kinyoun staining. The data are shown in Table 1.

Based on an epidemiological survey, the seroprevalence for a positive response to the $27-\mathrm{kDa}$ Cryptosporidium antigen was significantly higher in communities where the drinking water originated from surface water than in the control city 
Cryptosporidium spp. and subtypes detected in faecal samples from humans and cattle using PCR, Slovenia, 2000-2015

\begin{tabular}{|c|c|c|c|c|c|}
\hline $\begin{array}{l}\text { Type of } \\
\text { sample }\end{array}$ & Time period & $\begin{array}{l}\text { Cryptosporidium spp. } \\
\text { (number of specimens) }\end{array}$ & $\begin{array}{l}\text { Cryptosporidium subtypes (number of } \\
\text { specimens) }\end{array}$ & $\begin{array}{c}\text { Method (and } \\
\text { sequenced } \\
\text { molecular markers) }\end{array}$ & Reference \\
\hline \multirow{3}{*}{ Human } & \multirow{3}{*}{$2000-2006$} & C. hominis (2) & $\mathrm{IaA}_{17}(1), \mathrm{IbA}_{10} \mathrm{G}_{2}(1)$ & \multirow{3}{*}{$\begin{array}{l}\text { PCR (SSU rRNA, } \\
\text { gp6o) }\end{array}$} & \multirow{3}{*}[117,168]{} \\
\hline & & C. parvum (31) & 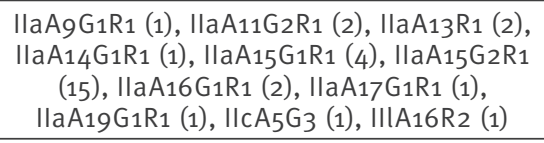 & & \\
\hline & & C. ubiquitum (1) & NA & & \\
\hline \multirow{3}{*}{ Human } & \multirow{3}{*}{$2007-2015$} & C. hominis (7) & $\operatorname{IaA} 20(1), \operatorname{IaA} 22$ (1), IaA23 (1), IdA14 (1) & \multirow{3}{*}{$\begin{array}{l}\text { PCR (SSU rRNA, } \\
\text { gp6o) }\end{array}$} & \multirow{3}{*}{$\begin{array}{l}\text { (Šoba et } \\
\text { al. data not } \\
\text { shown) }\end{array}$} \\
\hline & & C. parvum (32) & $\begin{array}{c}\text { IlaA11R1 (1), IlaA13R1 (10), IlaA15G2R1 (14), } \\
\text { IlaA15G1R1 (2), IlaA16R2 (1), IlaA16G1R1 (1), } \\
\text { IIaA17G1R1 (1), IlaA19G1R1 (1) }\end{array}$ & & \\
\hline & & C. meleagridis (1) & NA & & \\
\hline \multirow{3}{*}{ Bovine } & \multirow{3}{*}{$2002-2007$} & C. parvum (45) & $\begin{array}{l}\text { IlaA13R1 (5), IlaA15G2R1 (27), IlaA16R1 (3), } \\
\text { IlaA16G1R1 (6), IIIA16R2 (2), IIIA18R2 (2) }\end{array}$ & \multirow{3}{*}{$\begin{array}{l}\text { PCR (SSU rRNA, } \\
\text { gp6o) }\end{array}$} & \multirow{3}{*}{ [117] } \\
\hline & & C. bovis (3) & NA & & \\
\hline & & C. ryanae (3) & NA & & \\
\hline
\end{tabular}

NA: not available: SSU rRNA: small subunit ribosomal ribonucleic acid.

where riverbank filtration was used ( $p<0.001)$. A logistic regression analysis of risk factors showed that bathing in outdoor pools was also associated with a positive response to the $15 / 17-\mathrm{kDa}$ Cryptosporidium antigen complex $(p=0.0197)[67]$.

The association between the consumption of Giardiapositive drinking water and asymptomatic giardiasis was investigated in 2007. Despite this being a field investigation where only a single stool sample was examined from each participant, G. intestinalis infections were found in $4.00 \%$ (4/100; $95 \%$ $\mathrm{Cl}: 1.28-9.36)$ of asymptomatic individuals. In both water samples and asymptomatic persons, G. intestinalis assemblage B was detected [68].

\section{Animals}

A total of $49.37 \%(39 / 79 ; 95 \% \mathrm{Cl}: 38.46-60.32)$ of faecal samples from calves with diarrhoea collected on 52 farms in 2006 from different Hungarian counties showed positivity using IFT. Based on sequence and phylogenetic analysis, C. ryanae was detected in one sample and the gp6o gene PCR products of 21 isolates showed that two isolates belonged to the $C$. parvum IId subtype group (IIdA22 $\mathrm{G}_{1}$ and $I I d A_{19} G_{1}$ ) and the most common C. parvum subtype was llaA16G1R1 $(n=15)$. Other detected subtypes were $\|_{a A} A_{17} R_{1}(n=3)$ and IlaA18G1R1 ( $=1)$ [69].

In 2008, the combined results of a microscopic and molecular study indicated that aquatic ducks, geese, coot and cormorant may have a role in the environmental dissemination of human pathogenic assemblages of Cryptosporidiumoocysts and Giardia cysts. A total of $5.82 \%(6 / 103,95 \% \mathrm{Cl}: 2.39-11.72)$ of wild birds and $13.79 \%(4 / 29 ; 95 \% \mathrm{Cl}: 4.54-30.00)$ of domestic birds were C. parvum or C. baileyi positive. Additionally, $5.82 \%(6 / 103 ; 95 \% \mathrm{Cl}: 2.39-11.72)$ of samples from wild birds and $24.14 \%(7 / 29 ; 95 \% \mathrm{Cl}: 11.22-42.01)$ of samples from domestic birds were $G$. intestinalispositive [70].

In the past decade, the Central Veterinary Institute detected Cryptosporidium spp. in cattle, sheep and goats (Table 4 ).

Sporadic Cryptosporidium spp. infections have been found by the same institute in piglets, puppies and kittens. Infection by Giardia spp. was detected in $27.90 \%$ of chinchillas (48/172; $95 \% \mathrm{Cl}: 21.59-34.96)$. Sporadic Giardia spp. infections were also seen in cattle, sheep, dogs, cats and laboratory rats. The presence of $G$. intestinalis in kennel dogs from Hungary using a specific copro-antigen ELISA test was $58.82 \%$ (110/187; 95\% Cl: 51.66-65.72). All sequenced SSU rRNA samples belonged to dog-specific assemblages $C$ and D. Although canine giardiasis is highly prevalent in the studied geographical areas, it did not present zoonotic potential and the infection rate declined with increasing age of the dogs [71].

\section{Environment}

The presence of Cryptosporidium oocysts and Giardia cysts in different water sources (surface water, wastewater, raw water and drinking water) was investigated during the period 2000 to 2007 by microscopy using Method 1623 of the United States Environmental Protection Agency (US EPA). Up to three Cryptosporidium oocysts/100 L and up to 63.6 Giardia cysts/100 L were detected in drinking water [72]. The highest concentration in raw water was 50 Cryptosporidium oocysts/100 L and 
1,030 Giardia cysts/100 L. A higher concentration of oocysts was found in water sources that received effluents from sewage treatment plants or originated from a forest environment. Riverbank filtrated water $(n=71)$ and raw water from the Danube River ( $n=184$ ) in Budapest were monitored to document the protozoan removal efficiency by riverbank filtration (RBF) during the years 2004 to 2005 [72] and (Plutzer et al. data not shown). Cryptosporidium and Giardia spp. were detected regularly in the river water but never in riverbank filtered water, suggesting the effectiveness of RBF as a method of pathogen removal. Cryptosporidium spp. were detected in $36.41 \%$ of raw river water samples $(67 / 184 ; 95 \% \mathrm{Cl}: 29.70-$ 43.55) and Giardia spp. were detected in $96.74 \%$ of raw river water samples (178/184; 95\% Cl: 93.34-98.67) [72] and (Plutzer et al. data not shown). The species and genotypes determined by molecular tools were all potentially zoonotic: C. parvum, C. meleagridis and G. intestinalisassemblages $A$ and $B[72,73]$.

\section{Latvia}

Humans

The epidemiological data regarding Cryptosporidium and Giardia were collected from the Centre of Disease Prevention and Control of Latvia (Table 1). Cryptosporidiosis cases in humans have only been reported since 2009 , with a total of 57 cases being reported from then until 2015 (mean: 9 cases per year, range: $2-23$ cases per year). The highest number of reported cases occurred in the age group of 30-39 years olds: $42.11 \%(24 / 57 ; 95 \% \mathrm{Cl}: 29.83-55.16)$.

From 2000 to 2015, a total of 446 cases of giardiasis were reported (mean: 30 cases per year, range: 3-124 cases per year). The highest number of reported cases, 30.94\% (138/446; 95\% Cl: 26.78-35.35), was observed in the age group of 7-14 year olds. All diagnostics were conducted by analysing stool samples with the coproantigen test.

\section{Animals}

During a study conducted by the Faculty of Veterinary Medicine at the Latvia University of Agriculture between 2013 and 2014, a total of 1,580 faecal samples from dairy cattle were collected from different regions in Latvia. According to the microscopy results using Ziehl-Neelsen staining, Cryptosporidium oocysts were present in $19.43 \%(307 / 1,580 ; 95 \% \mathrm{Cl}$ : 17.54-21.44) of the samples. A lower prevalence of Cryptosporidium spp.-positive faecal samples was found $4.64 \%(18 / 388 ; 95 \% \mathrm{Cl}: 2.86-7.09)$ in the Latgale region than in other regions where prevalence ranged from 20.39\% (63/309; 95\% Cl: 16.17-25.16) to $26.38 \%(86 / 326 ; 95 \% \mathrm{Cl}: 21.81-31.37)$. An earlier study of 16 dairy farms and 125 animals found that $68.75 \%(11 / 16 ; 95 \% \mathrm{Cl}: 43.68-87.54)$ of the farms had at least one animal shedding Cryptosporidium spp. in their faeces; $40.80 \%(51 / 125 ; 95 \% \mathrm{Cl}: 32.44-$ 49.58) of the animals tested positive using modified
Ziehl-Neelsen staining of faecal smears [74]. There are no Cryptosporidium prevalence studies in other animal species. No studies have investigated the prevalence of giardiasis in animals, while sporadic G. intestinalisinfections are diagnosed in dogs and cats (personal communication, G Deksne, July 2016).

\section{Poland}

\section{Humans}

In Poland, human cryptosporidiosis and giardiasis cases are notifiable diseases. In the years 2005 to 2016, the National Institute of Public Health, National Institute of Hygiene in Poland reported one to six cases of human cryptosporidiosis and 2,288 cases of giardiasis per year (Table 1). Prevalence estimates of Crypt osporidium and Giardia spp. in humans are available from research studies, but these are limited to selected population groups and regions. For example, Cryptosporidium oocysts were detected by microscopy (examination of smears of faecal samples after modified Ziehl-Neelsen and IFT) in $14.63 \%$ (36/246; $95 \% \mathrm{Cl}: 10.62-19.47)$ of stool samples collected from hospitalised patients with diarrhoea [75]. All positive samples were from children up to 4 years of age, and isolates belonged to species C. parvum and C. hominis. In 2008, Bajer et al. reported Cryptosporidium infectio ns in persons with immunodeficiencies; $C$. hominis, $C$. meleagridis and $C$. parvum were found in children with primary immunodeficiencies (PID), but only $C$. parvum was found in children and adults with a secondary immunosuppression (i.e. after cancer treatment) [76].

A 2010 study including 232 people from the west-central region of Poland found $G$. intestinalis in $1.29 \%(3 / 232$; $95 \% \mathrm{Cl}: 0.33-3.48)$ of the collected faecal samples by direct microscopy. Three subgenotypes of Giardia were detected: a cosmopolitan subgenotype All and two new subgenotypes $A$ and $B$ [77]. Examination of the faeces of 31,504 children 7 years of age from 15 Polish provinces in 2002 to 2003 found $G$. intestinalis in the faeces of $0.69 \%(217 / 31,504 ; 95 \% \mathrm{Cl}: 0.60-0.78)$ of the children using direct microscopy and Lugol's iodine staining method [78]. In another study from 2008 to 2009 , of 120 children with watery diarrhoea resembling a parasite infection, $12.50 \%\left(15 / 120 ; 95 \% \mathrm{Cl}: 7.44^{-}\right.$ 19.35) tested positive for Giardia antigens in the faeces using an immunochromatographic test [79].

\section{Animals}

Several prevalence studies have been performed on animals in Poland for both parasites using a wide range of detection techniques. The results are summarised in Table 5 .

\section{Environment}

Cryptosporidium spp. contamination of tap water has been confirmed by microscopy, IFA and PCR in one of twelve examined samples from the city of Poznan [80]. 
Examination of surface waters

The presence of $G$. intestinalis assemblages $A$ and $B$, and Cryptosporidium oocysts has been found in $45.57 \%$ (36/79; 95\% Cl: 34.84-56.61) and 32.91\% (26/79; 95\% $\mathrm{Cl}: 23.24-43.82)$ of samples taken from Mazurian Lake, respectively [81]. The Vistula River $(n=21)$ and the Zegrzyński Lake $(n=8)$ were tested for the presence of Cryptosporidium oocysts and Giardia cysts using a Filta-Max filtration capsules and xpress automatic station (IDEXX Laboratories, Inc., Westbrook, US) for filter elution, immunomagnetic separation (IMS) and IFT [82]. Giardia cysts were found in all samples from the Zegrzynski Lake (range: 10-45/100 $\mathrm{L})$ and in all samples from the Vistula River (range: 10-389/100 L). Cryptosporidium oocysts were present in $50.00 \%(4 / 8 ; 95 \% \mathrm{Cl}: 18.41-81.59)$ of samples from the Zegrzyński Lake and in $47.62 \%(10 / 21 ; 95 \% \mathrm{Cl}$ : 27.29-68.57) of samples from the Vistula River. Their number in both cases was similar and ranged from 5 to 25 oocyst/10o L. Cryptosporidium oocysts were also detected in 50 of 68 surface water samples collected monthly from intakes $(n=13)$ and recreational waters $(n=4)$ in the Krakow area during June to September 2012. Giardia cysts were only detected in samples taken from three sampling locations [83].

Examination of sewage waters

Cryptosporidium spp. oocysts were detected in $61.54 \%$ (8/13; 95\% Cl: $34.09-84.32)$ of wastewater treatment plants (WWTPs) and Giardia spp. cysts in $84.61 \%$ (11/13; 95\% Cl: $57.77-97.34)$ of WWTPs in eastern Poland by microscopic analyses using Method 1623 of the US EPA [84]. Cryptosporidium oocyst concentrations in raw sewage water ranged from 40 to 15,410 oocysts/100 $\mathrm{L}$ and Giardia cyst concentrations ranged from 70 to 66,000 cysts/100 L.

Using animals as indicators of contamination

Rotifers taken from three lakes located near the city of Poznań were used as an indicator of recreational water contamination [85]. Cryptosporidium oocysts were detected in rotifers and water from the lakes using the fluorescence in situ hybridisation (FISH) method. Mussels collected from Poznań's municipal reservoir, Lake Malta, have been examined by direct microscopy (wet smear and smears stained with Ziehl-Neelsen and iron haematoxylin) and MERIFLUOR IFT Cryptosporidium/Giardia kit (Meridian Bioscience Inc., Cincinnati, US) [86]. Cryptosporidium oocysts were detected in $15.38 \%(12 / 78 ; 95 \% \mathrm{Cl}: 8.61-24.69)$ of the mussels.

Contamination of food products

Fresh vegetables and soft fruit have been investigated using IMS and molecular methods [87]. Cryptosporidiumoocysts were found on 6 of 128 vegetables, and $C$. parvum was identified by subtyping (gp6o) from celery. The authors speculated that the presence of Cryptosporidium on vegetables could be associated with products originating from regions with considerable livestock production [87].

\section{Romania}

Humans

Between 2008 and 2012, a total of 16 Cryptosporidium spp. infections were reported by the Romanian National Public Health Institute (Table 1). In a study using ELISA, a Cryptosporidium prevalence of $4.04 \%(17 / 421 ; 95 \% \mathrm{Cl}: 2.45-6.26)$ was reported from western Romania [88]. Molecular characterisation of five isolates indicated the presence of species C. parvum $(\mathrm{n}=3)$ and C. ubiquitum $(\mathrm{n}=2)$ [88]. Vieira et al. has also reported the presence of the $C$. parvum subtype $I I d A 22 G_{1}$ in faecal samples of four children under 12 years of age from Timiş County in this area of Romania [89].

Data provided by the Romanian National Public Health Institute for a 6-year period (2010 to 2015) of routine investigation of patients with gastrointestinal disorders showed a cumulative Giardia infection prevalence of $5.70 \%(106,682 / 1,870,475 ; 95 \% \mathrm{Cl}: 5.60-5.81)$. Data from 269 hospitalised patients between 1996 and 2008 from Caraş-Severin County indicated Giardia infections in $7.81 \%(21 / 269 ; 95 \% \mathrm{Cl}: 5.03-11.49)$ of individuals [90]. In addition, a study conducted by Costache et al. between 2008 and 2011 in Cluj County and neighbouring areas reported a cumulative giardiasis prevalence of $0.41 \%(76 / 18,486 ; 95 \% \mathrm{Cl}: 0.33-0.51)$ in children and of $0.80 \%(141 / 17,645 ; 95 \% \mathrm{Cl}: 0.67-0.94)$ in the adult general population [91].

Animals

Over the last decade, epidemiological surveys were carried out with the aim of finding Cryptosporidium oocysts and Giardia cysts in livestock, pets and wildlife stool samples. Research focusing on livestock is limited and mostly involves the western [89,92-94], central and north-western [95] regions of the country. The methods applied included non-molecular (conventional acid-fast staining and classical microscopic examination, coproantigen detection immunoassays) and molecular tools (PCR-restriction fragment length polymorphism (RFLP), DNA sequencing). Results are summarised in Table 6.

Environment

Investigations on the occurrence of Cryptosporidium spp. oocysts and Giardia spp. cysts in the main rivers of western Romania using the US EPA's Method 1623 showed their presence in $7.54 \%(4 / 53 ; 95 \% \mathrm{Cl}: 2.44-17.21)$ and $41.50 \%(22 / 53$; $95 \% \mathrm{Cl}: 28.87-55.06)$ of raw surface water samples, respectively. Genetic characterisation of the isolates demonstrated the presence of domestic/wild canid origin $C$. canis $(n=1)$ and the human/animal origin $C$. parvumllaA16G1R1 subtype $(n=1)$, as well as $G$. intestinalis assemblages All $(n=12)$ and $E$, the ruminant origin assemblage $(n=1)$ [96]. In another study, conducted in the same region, $27.27 \%(3 / 11 ; 95 \% \mathrm{Cl}$ : 7.45-57.81) of the tested wastewater samples were positive for the zoonotic $C$. parvum, with IlaA15G2R1 $(n=2)$ and $I I d A 18 G_{1}$ subtypes. Also, the occurrence 
of Giardia spp. were recorded in different surface water types with a detection rate of $90.91 \%(10 / 11 ; 95 \% \mathrm{Cl}$ : $62.66-99.55)$ in wastewaters, $26.31 \%(5 / 19 ; 95 \% \mathrm{Cl}$ : 10.34-49.06) in brooks, $37.50 \%(3 / 8 ; 95 \% \mathrm{Cl}: 10.56-$ 72.20) in irrigation channels, $31.25 \%(5 / 16 ; \mathrm{Cl}: 12.46-$ $56.32)$ in lakes, and $36.36 \%(8 / 22 ; \mathrm{Cl}: 18.53-57.59)$ in ponds. The registered and successfully sequenced $G$. intestinalis assemblages were: assemblage $E(n=12)$ in all tested water bodies, assemblage All $(n=9)$ in all tested water bodies except for ponds, and the domestic/wild canid specific assemblage $D$ in a pond [97].

\section{Serbia}

\section{Humans}

In Serbia, giardiasis is a notifiable disease, while cryptosporidiosis is not. Not only that cryptosporidiosis is not reportable, it has also seldom been the subject of research. The only description of cryptosporidiosis in immunocompetent individuals is a report of a family outbreak in 2010 [98]. Conversely, a long-term analysis in immunocompromised individuals carried out between 1985 and 2008 found cryptosporidiosis in $10.50 \%(50 / 476 ; 95 \% \mathrm{Cl}: 7.98-13.50)$ of HIV-infected patients with gastrointestinal symptoms. This finding placed cryptosporidiosis as the second most common cause of gastrointestinal disorders, following oesophageal candidiasis, among all opportunistic diseases in this patient category [99].

On the other hand, giardiasis apparently occurs much more frequently. From 2005 to 2014, a total of 1,996 cases of giardiasis (Table 1) were reported by the Institute of Public Health of Serbia [100]. However, the number of examinations carried out, the clinical reasons for testing and the methods used in particular laboratories are not reported. Analysis of the reports showed that the number of reported cases of giardiasis decreased from 4.6 per 100,000 inhabitants in 2005 to 1.1 per 100,000 inhabitants in 2014 . There was no difference $(p=0.255)$ in the distribution of cases between females and males ( $48.5 \%$ of cases were female and $51.5 \%$ were male). Infections were most often diagnosed in people aged $20-40$ (45.6\%), while $11.9 \%$ of all cases were reported in children up to 10 years of age. Giardiasis occurrence was associated with seasonality ( $p<0.0001)$, with one third of the cases being diagnosed between August and October. The incidence peak coincided with increased outdoor activities and increased water consumption during hot weather periods. Giardiasis is widespread throughout Serbia, but the data seem to indicate that it is more common in northern than in central Serbia (10-year mean of 4.5 cases/100,000 inhabitants vs 2.1 cases/100,000 inhabitants). Whether the observed fluctuations reflect a real change in the infection dynamics or are merely the result of differences in the detection of cases or reporting of these remains to be explored. Official reports do not differentiate between cases and do not describe whether reported cases were symptomatic or accidental findings of possibly asymptomatic individuals, for example, during routine examinations of cooks, bakers, restaurant staff, etc. for obligatory occupational health checks. Regional investigations conducted by the Department for Parasitology at the Public Health Centre of Niš (southern Serbia) between 2004 and 2008, did report the number of investigations making it possible to estimate the prevalence of Giardia, which was $0.28 \%$ (Table 1). MiladinovicTasic and colleagues carried out several studies on giardiasis in different populations; the results from ones that examined healthy adults as a part of obligatory occupational health checks showed a decrease in the prevalence of giardiasis from $0.43 \%(64 / 14,833$; $95 \% \mathrm{Cl}: 0.33-0.55)$ in 2002 to $0.16 \%(53 / 32,814 ; 95 \%$ $\mathrm{Cl}: 0.12-0.21)$ in 2008 [101-103]. High infection rates were registered in establishments where people were in close contact, such as individuals in psychiatric institutions (6/100; 6.00\%, 95\% Cl: 2.47-12.06) [101], specialised institutions for children with disabilities (7/106; 6.60\%, 95\% Cl: 2.93-12.62) [101] and refugee camps (7/122; $5.74 \%, 95 \% \mathrm{Cl}: 2.54-11.02)$ [102]. In patients with diarrhoea, the prevalence of giardiasis was as high as $10 \%$ in adults and $4 \%$ in children under 14 years of age $[101,102]$. The prevalence of giardiasis has also been studied in schoolchildren. Nikolić et al conducted an extensive long-term study throughout central Serbia between 1985 and 2005 that involved a total of 6,645 asymptomatic children 7-11 years of age, representing approximately $10 \%$ of the total agematched population $(n=69,232)$ [104]. The methods used included microscopy after conventional concentration techniques. Despite this being a field investigation where only a single stool sample was examined from each participant, the results showed the presence of Giardia infection in all examined regions, with infection rates ranging from 3.2 to $14.2 \%$, and an overall prevalence of $6.10 \%(405 / 6,645 ; 95 \% \mathrm{Cl}$ : 5.54-6.69). This is significantly higher than the figures in the official reports. Interestingly, the prevalence of Giardia was similar in urban (7.0\%) and rural (6.5\%) areas. Another study had previously shown a similarly high prevalence of $8.00 \%$ (14/175; 95\% Cl: 4.63-12.76) in the highly urban area of the city of Belgrade [105]. Finally, a study carried out in 2004 in south-western Serbia estimated a giardiasis prevalence of $5.62 \%$ (45/800; $95 \% \mathrm{Cl}: 4.18-7.39)$ in asymptomatic schoolchildren [106].

\section{Animals}

Neither Cryptosporidium nor Giardia infections are notifiable in animals in Serbia. However, several studies have investigated such infections in cattle, swine, lambs and goats (Table 7).

In an examination of 160 cattle from the Belgrade area, Cryptosporidium oocysts were detected in $34.61 \%$ (9/26; $95 \% \mathrm{Cl}: 18.38-54.11)$ of weaners, $49.02 \%$ (25/51; 95\% Cl: $35.55-62.60)$ of bull calves and $47.50 \%$ (38/80; $95 \% \mathrm{Cl}: 36.74-58.44)$ of post parturient cows [107]. Another study showed a prevalence of $60.20 \%$ (62/103; 
95\% Cl: 50.52-69.30) among dairy calves up to 1 month of age [108]. Cryptosporidium oocysts were also found in the faeces of $34.23 \%$ (89/260; $95 \% \mathrm{Cl}: 28.65-40.16)$ of swine with an observed decrease with age [109]. To expand, oocysts were detected in 45.55\% (41/90; $95 \%$ $\mathrm{Cl}: 35.49-55.91)$ of nursing, weaning and post-weaned piglets up to 3 months of age, in $32.80 \%(41 / 125 ; 95 \%$ Cl: $25.00-41.39)$ of post-weaned piglets 3 to 12 months of age, and in $15.55 \%(7 / 45 ; 95 \% \mathrm{Cl}: 7.07-28.36)$ of sows older than 12 months of age. In all pigs older than 3 months of age, the Cryptosporidium infection was subclinical [109].

Infections with Giardia were studied in 2008 in Belgrade-area dogs and cats (Table 7). In dogs, the infection rate depended on living conditions. The lowest prevalence was detected in pet household dogs (7.41\%, 6/81; 95\% Cl: 3.06-14.77), followed by a higher prevalence in stray $(18.67 \%, 14 / 75 ; 95 \% \mathrm{Cl}: 11.04-$ $28.68)$ and kennel dogs $(36.36 \%, 4 / 11 ; 95 \% \mathrm{Cl}: 12.78-$ 66.36) [110]. A 2015 study in shelter dogs, however, showed a remarkably higher prevalence of infections with Giardia of $65.67 \%$ (88/134; 95\% Cl: $57.33-73.34)$ belonging to the assemblages C and D [111]. In 2001, a study found a higher Giardia prevalence in kittens (7/23; 30.43\%, 95\% Cl: 14.39-51.14) than in adult pet cats $(11 / 58 ; 18.96 \%, 95 \% \mathrm{Cl}: 10.40-30.57)$, however all 95\% Cls overlapped [112]. Other data from 2012 seemed to indicate a decrease in the Giardia infection rate in cats [113].

\section{Slovenia}

\section{Humans}

Between 2002 and 2015, patients with diarrhoea ( $n=5,106)$ were examined for Cryptosporidium oocysts by IFT and patients with various gastrointestinal and/ or digestive disorders and/or diseases $(n=24,782)$ were examined for the presence of $G$. intestinalis cysts by iodine wet mount microscopy and/or IFT at the Institute of Microbiology and Immunology (IMI), Faculty of Medicine at the University of Ljubljana. It was found that $78 / 5,106$ (1.53\%) and $237 / 24,782$ (0.96\%) patients were Cryptosporidium and G. intestinalis positive, respectively (personal communication, B Šoba, November 2016) (Table 1). In the same period (2002-2015), 121 cases of cryptosporidiosis and 574 cases of giardiasis were reported to the National Institute of Public Health of the Republic of Slovenia (NIJZ), with a mean cryptosporidiosis and giardiasis incidence of 0.42 and 2.02 per 100,000 inhabitants in Slovenia, respectively [114]. Cryptosporidium species and subtypes identified from human samples are summarised in Table 8.

From 2002 to 2013, a total of $51 \mathrm{G}$. intestinalis isolates from symptomatic human cases were genetically characterised. Assemblage A was found in $50.98 \%$ (26/51; $95 \% \mathrm{Cl}: 37.40-64.45)$ of the isolates while the remaining $49.02 \%(25 / 51 ; 95 \% \mathrm{Cl}: 35.55-62.60)$ of the isolates were of the assemblage $\mathrm{B}$. Phylogenetic analysis showed that the successfully subtyped assemblage $A$ isolates belonged to the sub-assemblage All while the assemblage $B$ isolates belonged to the sub-assemblage BIV [115].

Animals

According to genotyping studies, the transmission of Cryptosporidium between cattle and humans is of epidemiological relevance in Slovenia. The most common C. parvum subtypes in cattle were also found in humans $[116,117]$. The Cryptosporidium species and subtypes detected in cattle in Slovenia are presented in Table 8.

Faecal samples from cattle $(n=391)$, sheep $(n=35)$, goats $(n=9)$, horses $(n=14)$ and deer $(n=28)$, were examined for Giardia cysts using IFT in 2006-2007. Of the examined samples, $26.60 \%(104 / 391 ; 95 \% \mathrm{Cl}$ : $22.40-31.15)$ of cattle, $42.86 \%(15 / 35 ; 95 \% \mathrm{Cl}: 27.35-$ $59.50)$ of sheep and $11.11 \%(1 / 9 ; 95 \% \mathrm{Cl}: 0.55-43.86)$ of goats were found to be Giardia-positive, while no cysts were found in horses and deer. In terms of cattle, only the non-zoonotic assemblage $E$ of $G$. intestinalis has been found in 36 faecal samples from livestock using a real-time PCR assay [118]. Although the sample size is limited, the results of this study suggest a less important role of livestock in the transmission of Giardiato humans in Slovenia.

\section{Discussion}

Analysis of the data obtained from a total of 10 countries showed that both Cryptosporidium spp. and Giardia spp. are commonly found in animals and in the environment when investigated, while giardiasis is more commonly reported in humans than cryptosporidiosis. Based on the number of reported cases in the ECDC Surveillance Atlas of Infectious Diseases, the difference between western Europe and eastern Europe appears more striking for cryptosporidiosis than for giardiasis [11].

Both parasites are prevalent in eastern Europe, but the number of reported cases varies greatly between the investigated countries; the causes of this variation include true differences in exposure and susceptibility, variable provision and access to healthcare systems, and differences in case definition, laboratory diagnosis, recording of cases and reporting. The national health systems of the countries covered here operate differently. Eight countries are members of the $\mathrm{EU}$, and in these, both cryptosporidiosis and giardiasis are notifiable. In Bosnia and Herzegovina, neither disease is notifiable, and in Serbia, only giardiasis is notifiable. The different reporting standards may lead to varied levels of underreporting and varied recognition of the diseases as public health issue. Making a disease mandatorily notifiable is an important step for obtaining accurate data, however, the quality and representativeness of the data obtained depends strongly on which patients are tested and which diagnostic tests are used. In many countries, neither the 
number of samples investigated nor the methods used for testing are reported. In our opinion, more transparency and uniformity in the collection of surveillance data are needed to further improve its quality. Currently, data available from the ECDC Surveillance Atlas of Infectious Diseases does not allow for reliable inter-country comparisons as demonstrated by the discrepancy in the reported occurrence of both diseases in humans when comparing surveillance data available via in the ECDC Surveillance Atlas of Infectious Diseases with the data provided by the public health laboratories (Table 1). Some countries provided lower or higher notification rates than that reported by public health laboratories. For example, no evidence of human infections of $G$. intestinalis was recorded for Romania in the ECDC Surveillance Atlas of Infectious Diseases (Table 1). Primary care doctors or physicians frequently treat patients with diarrhoeal disease symptomatically, without testing faecal samples for pathogens.

Another striking observation of our analysis is the discrepancy in the number of human cases between official reports of public health authorities (Table 1) and research-derived data. Although routine investigations and research studies are never directly comparable, the studies indicate more human infections than what is reflected in the routine investigations, therefore suggesting under-reporting throughout eastern Europe. One reason why research studies report more cases than public health authorities may be the ability to use more sophisticated methodology than that available for routine purposes. Under-reporting, which leads to underestimation of the burden of infection, is further anticipated because not all infected individuals exhibit clinical symptoms and some symptomatic persons do not seek medical care.

Data on the occurrence of Cryptosporidium spp. and Giardia spp. in animals in eastern Europe differ broadly in terms of targeted animal species and depth of analysis. This review showed that both Cryptosporidium spp. and Giardia spp. are common parasites of domestic animals, including pets, in eastern Europe, and importantly, genotypes pathogenic to humans, including C. parvum and $G$. intestinalis assemblage $\mathrm{A}$ and $\mathrm{B}$, are prevalent. C.parvum subtype IlaA16G1R1 is a common subtype in the region, found in both cattle and humans in the Czech Republic, Estonia, Hungary, Romania and Slovenia $[62,69,89,117,119]$. It has also been suggested that birds may be carriers of human pathogenic species and genotypes of Giardia and Cryptosporidium [70].

Analysis of the current status of research on Cryptosporidium spp. and Giardia spp. in the environment highlighted that to date, relatively little is known about the occurrence and genetic diversity of these parasites in natural water supplies. Reports were available from the Czech Republic, Hungary, Poland and Romania [24,55-58,72,73,80-84,96-97].
Reports on presence of Cryptosporidium spp. and Giardia spp. in food were scarce from this region. Waterborne and food-borne outbreaks are clearly important to establish the burden of disease, but it is likely that many smaller outbreaks are currently missed $[120,121]$.

Baseline data as well as improved understanding of the epidemiology, infection sources, reservoirs and transmission of cryptosporidiosis and giardiasis in eastern Europe are needed. Surveillance studies and outbreak investigations using molecular tools at the subtype level are warranted. In addition, consensus and updated methods that are harmonised across countries are required to make the data more comparable. Reducing public health risks from zoonoses and other threats at the human-animal-ecosystem interface must consider the complexity of interactions among humans, animals and the various environments in which they live. This requires communication and collaboration among the sectors responsible for human health, animal health and the environment in a One Health approach. Although the presented results may be important for public health specialists, epidemiologists, drinking and wastewater managers, veterinarians, farmers and the public in general, further addressing the knowledge gaps in a timely manner would greatly contribute to understanding the complex picture of cryptosporidiosis and giardiasis epidemiology and thus set the stage for appropriate future control plans.

\section{Acknowledgements}

The authors received funding/support from the following sources:

- Scandinavian-Baltic Society for Parasitology funding of parasitological reviews.

- Base Financing of the Estonian University of Life Sciences (project 8P160014VLVP).

- Romanian National Authority for Scientific Research and Innovation, CNCS National University Research Council (CNCS) and Executive Agency for Higher Education, Research, Development and Innovation Funding (UEFISCDI) (project grant number PN-II-RU-TE-2014-4-1300).

- Czech Science Foundation (project number 15-01090S).

- The Serbian Ministry of Education, Science and Technological Development (project grant number III41019).

- The One Thousand Talents Plan of the Chinese Government (project grant number WQ2013630172).

- The Slovenian Research Agency (research core funding number $\mathrm{P}_{3}$-0083).

The Polish Ministry of Science and Higher Education (project grant number NN308577039).

The article is partly based upon collaboration within the framework of COST Action FA1408 (A European Network 
for Foodborne Parasites (Euro-FBP)), supported by COST (European Cooperation in Science and Technology)

We also acknowledge the kind help of the following individuals:

Pál Szakál for editorial work on this manuscript, Age Kärssin for helping to summarise the veterinary diagnostic data from Estonia, Eszter Mezei for retrieving the epidemiological data from Hungary, Antra Bormane and Rita Korotinska from the Latvian Disease and Control Centre for providing the epidemiological data from Latvia.

\section{Conflict of interest}

None declared.

\section{Authors' contributions}

Judit Plutzer coordinated the data collection and wrote the manuscript.

Brian Lassen collected the data from Estonia and wrote the manuscript.

Pikka Jokelainen collected the data from Estonia and wrote the manuscript.

Olgica Djurković-Djaković collected the data from Serbia and wrote the manuscript.

István Kucsera collected the data from Hungary and prepared the summary.

Elisabeth Dorbek-Kolin collected the data from Estonia and prepared the summary.

Barbara Šoba collected the data from Slovenia and prepared the summary.

Tamás Sréter collected the data from Hungary and prepared the summary.

Kálmán Imre collected the data from Romania and prepared the summary.

Jasmin Omeragic collected the data from Bosnia and Herzegovina and prepared the summary.

Aleksandra Nikolic collected the data from Serbia and prepared the summary.

Branko Bobic collected the data from Serbia and prepared the summary.

Tatjana Živičnjak collected the data from Croatia and prepared the summary.

Snježana Lučinger collected the data from Croatia and prepared the summary.

Lorena Lazarić Stefanović collected the data from Croatia and prepared the summary.

Jasmina Kučinar collected the data from Croatia and prepared the summary.

Jacek Sroka collected the data from Poland and prepared the summary.

Gunita Deksne collected the data from Latvia and prepared the summary.
Dace Keidāne collected the data from Latvia and prepared the summary.

Martin Kváč collected the data from Czech Republic and prepared the summary.

Zuzana Hůzová collected the data from Czech Republic and prepared the summary.

Panagiotis Karanis presented the idea for this study.

All authors have edited, read and approved the manuscript.

\section{References}

1. Food and Agriculture Organization of the United Nations/World Health Organization (FAO/WHO). Multicriteria-based ranking for risk management of food-borne parasites. Microbiolological Risk Assessment Series No. 23. Rome: FAO/WHO. 2014. Available from: http://www.fao.org/3/a-i3649e.pdf

2. Xiao L, Feng Y. Zoonotic cryptosporidiosis. FEMS Immunol Med Microbiol. 2008;52(3):309-23. https://doi.org/10.1111/j.1574695X.2008.00377.x PMID: 18205803

3. Sprong $\mathrm{H}$, Cacciò SM, van der Giessen JW. Identification of zoonotic genotypes of Giardia duodenalis. PLoS Negl Trop Dis. 2009;3(12):e558. https://doi.org/10.1371/journal. pntd.0000558 PMID: 19956662

4. World Health Organization (WHO). WHO estimates of the global burden of foodborne diseases: foodborne disease burden epidemiology reference group 2007-2015. Geneva: WHO. 2015. [Accessed 15 Dec 2017]. Available from: http://apps.who.int/ iris/bitstream/10665/199350/1/9789241565165_eng.pdf?ua=1

5. Lake RJ, Devleesschauwer B, Nasinyama G, Havelaar AH, Kuchenmüller T, Haagsma JA, et al. National Studies as a Component of the World Health Organization Initiative to Estimate the Global and Regional Burden of Foodborne Disease. PLoS One. 2015;10(12):e0140319. https://doi. org/10.1371/journal.pone.0140319 PMID: 26633010

6. Tallant C, Huddleston P, Alshanberi A, Misra S. Acute, Severe Cryptosporidiosis in an Immunocompetent Pediatric Patient. Clin Pract. 2016;6(2):837. https://doi.org/10.4081/cp.2016.837 PMID: 27478580

7. Current WL, Garcia LS. Cryptosporidiosis. Clin Lab Med. 1991;11(4):873-97. PMID: 1802526

8. Pasmans F, Blahak S, Martel A, Pantchev N. Introducing reptiles into a captive collection: the role of the veterinarian. Vet J. 2008;175(1):53-68. https://doi.org/10.1016/j. tvjl.2006.12.009 PMID: 17346998

9. Farthing MJ. Giardiasis. Gastroenterol Clin North Am. 1996;25(3):493-515. https://doi.org/10.1016/So8898553(05)70260-0 PMID: 8863037

10. Upcroft IA, McDonnell PA, Gallagher AN, Chen N, Upcroft P. Lethal Giardia from a wild-caught sulphur-crested cockatoo (Cacatua galerita) established in vitro chronically infects mice. Parasitology. 1997;114(5):407-12. https://doi.org/10.1017/ So031182096008724 PMID: 9149411

11. European Centre for Disease Prevention and Control (ECDC). Surveillance Atlas of Infectious Diseases. Years 2007-2016. Stockholm: ECDC. [Accessed 12 Dec 2017]. Available from: http://atlas.ecdc.europa.eu/public/index. aspx? Instance $=$ GeneralAtlas

12. Eurostat. Population as a percentage of EU28 population, 2016. Luxembourg: Eurostat. [Accessed 12 Dec 2017]. Available from: http://ec.europa.eu/eurostat/tgm/table.do?tab=table\&init=1\& language $=$ en $\&$ pcode $=$ tpso0005\&plugin $=1$

13. Dean AG, Sullivan KM, Soe MM. OpenEpi: Open Source Epidemiologic Statistics for Public Health: version 3.01. Atlanta: OpenEpi. 2013. [Accessed 15 Dec 2017]. Available from: www.OpenEpi.com

14. Hodžić A, Alić A, Omeragić J. Occurrence of Cryptosporidium spp. and Giardia duodenalis in Red foxes (Vulpes vulpes) in Bosnia and Herzegovina. Macedonian Veterinary Review.2014;37(2):189-92. https://doi.org/10.14432/j. macvetrev.2014.04.012

15. Omeragić J, Hrvat H, Crnkić Ć. Occurrence of protozoa in dogs in the area of Tuzla. Proceedings of the International Congress 'One World - One Health - One Vision'; 2015 Oct 1416; Sarajevo, Bosnia and Herzegovina. Available from: https:// www.researchgate.net/publication/322267355

16. Hrvat H. Investigation of protozoa from the class of Sporozoea and Zoomastigophorea of dogs in area of northeast Bosnia. 
[Msc thesis]. Sarajevo: Veterinary Faculty, University of Sarajevo; 2015.

17. Klarić D, Radetić V, Gajić N, Cviko A, Grabovica E, Smajlović A, et al. Control of parasites in the kennel of Belgian shepherd dog. Proceedings of the International Congress 'One World One Health - One Vision'; 2015 Oct 14-16; Sarajevo, Bosnia and Herzegovina. Available from: https://www.researchgate.net/ publication/306018973

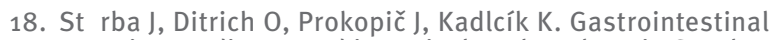
parasitoses discovered in agricultural workers in South Bohemia, Czechoslovakia. Folia Parasitol (Praha). 1988;35(2):169-73. PMID: 3169645

19. Breza M. The improvement of method of coproovascopical examination of pig faeces by using a new floatative solution Mucogel Liquid. Veterinársky Cas.1959;8:569-76.

20. Hunter GW 3rd, Hodges EP, Jahnes WG, Diamond LS, Ingalis JW. Studies of Schistosomiasis: II Summary of further studies on methods of recovering eggs of S. japonicum from stools. Bull U S Army Med Dep. 1948;8(2):128-31. PMID: 18909930

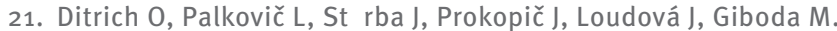
The first finding of Cryptosporidium baileyi in man. Parasitol Res. 1991;77(1):44-7. https://doi.org/10.1007/BFo0934383 PMID: 1825238

22. Milácek $P$, Vítovec J. Differential staining of cryptosporidia by aniline-carbol-methyl violet and tartrazine in smears from feces and scrapings of intestinal mucosa. Folia Parasitol (Praha). 1985;32(1):50. PMID: 2580763

23. Chmelík V, Ditrich O, Trnovcová R, Gutvirth J. Clinical features of diarrhoea in children caused by Cryptosporidium parvum. Folia Parasitol (Praha). 1998;45(2):170-2. PMID: 9684327

24. Hajdušek O, Ditrich O, Šlapeta J. Molecular identification of Cryptosporidium spp. in animal and human hosts from the Czech Republic. Vet Parasitol. 2004;122(3):183-92. https:// doi.org/10.1016/j.vetpar.2004.04.005 PMID: 15219359

25. Kváč $M$, Květoňová D, Sak B, Ditrich O. Cryptosporidium pig genotype II in immunocompetent man. Emerg Infect Dis. 2009b;15(6):982-3. https://doi.org/10.3201/eid1506.071621 PMID: 19523313

26. Rašková V, Květoňová D, Sak B, McEvoy J, Edwinson A, Stenger $B$, et al. Human cryptosporidiosis caused by Cryptosporidium tyzzeri and C. parvum isolates presumably transmitted from wild mice. J Clin Microbiol. 2013;51(1):360-2. https://doi. org/10.1128/JCM.02346-12 PMID: 23100342

27. Kváč M, Saková K, Kv $\square$ toňová D, Kicia M, Wesołowska M, McEvoy J, et al. Gastroenteritis caused by the Cryptosporidium hedgehog genotype in an immunocompetent man. J Clin Microbiol. 2014C;52(1):347-9. https://doi.org/10.1128/ JCM.02456-13 PMID: 24131692

28. Kožišek F, Craun GF, Cerovska L, Pumann P, Frost F, Muller T. Serological responses to Cryptosporidium-specific antigens in Czech populations with different water sources. Epidemiol Infect. 2008;136(2):279-86. https://doi.org/10.1017/ So950268807008370 PMID: 17394676

29. Pospísilová Z, Ditrich O, Stanková M, Kodym P. Parasitic opportunistic infections in Czech HIV-infected patients--a prospective study. Cent Eur J Public Health. 1997;5(4):208-13. PMID: 9457423

30. Koudela B, Vítovec J, Stロrba J, Milácek P. An unusual localization of developmental stages of Cryptosporidium parvum Tyzzer, 1912 in the cells of small intestine of a gnotobiotic piglet. Folia Parasitol (Praha). 1989;36(3):219-22. PMID: 2583612

31. Koudela B, Modrý D, Vítovec J. Infectivity of Cryptosporidium muris isolated from cattle. Vet Parasitol. 1998;76(3):1818. https://doi.org/10.1016/S0304-4017(97)00217-3 PMID 9615952

32. Vítovec J, Koudela B. Pathogenesis of intestinal cryptosporidiosis in conventional and gnotobiotic piglets. Vet Parasitol. 1992;43(1-2):25-36. https://doi.org/10.1016/03044017(92)90045-B PMID: 1496800

33. Koudela B, Boková A. The effect of cotrimoxazole on experimental Cryptosporidium parvum infection in kids. Vet Res. 1997;28(4):405-12. PMID: 9257448

34. Koudela B, Jirí V. Experimental cryptosporidiosis in kids. Vet Parasitol. 1997;71(4):273-81. https://doi.org/10.1016/S03044017(97)00024-1 PMID: 9299696

35. Vítovec J, Hamadejová K, Landová L, Kváč M, Květoňová D, Sak B. Prevalence and pathogenicity of Cryptosporidium suis in pre- and post-weaned pigs. J Vet Med B Infect Dis Vet Public Health. 2006;53(5):239-43. https://doi.org/10.1111/j.14390450.2006.00950.x PMID: 16732883

36. Kváč M, Ditrich 0 , Kouba $M$, Sak B, Vítovec J, Květoňová D. Failed attempt of Cryptosporidium andersoni infection in lambs. Folia Parasitol (Praha). 2004;51(4):373-4. https://doi. org/10.14411/fp.2004.047 PMID: 15729951
37. Kváč $M$, Kestřánová $M$, Pinková $M$, Květoňová $D$, Kalinová J, Wagnerová P, et al. Cryptosporidium scrofarum n. sp. (Apicomplexa: Cryptosporidiidae) in domestic pigs (Sus scrofa). Vet Parasitol. 2013a;191(3-4):218-27. https://doi. org/10.1016/j.vetpar.2012.09.005 PMID: 23021264

38. Kváč M, Ondráčková Z, Květoňová D, McEvoy J, Vítovec J, Rost $M$, et al. The Lesser Egyptian Gerbil (Gerbillus gerbillus) is a suitable host for the long-term propagation of Cryptosporidium andersoni. Exp Parasitol. 2013d;134(4):438-42. https://doi. org/10.1016/j.exppara.2013.04.007 PMID: 23644354

39. Kváč M, Hofmannová L, Hlásková L, Květoňová D, Vítovec J, McEvoy J, et al. Cryptosporidium erinacei n. sp. (Apicomplexa: Cryptosporidiidae) in hedgehogs. Vet Parasitol. 2014a;201(12):9-17. https://doi.org/10.1016/j.vetpar.2014.01.014 PMID: 24529828

40. Kváč $M$, Němejc K, Kestřánová $M$, Květoňová D, Wagnerová $P$, Kotková $M$, et al. Age related susceptibility of pigs to Cryptosporidium scrofarum infection. Vet Parasitol. 2014b;202(3-4):330-4. https://doi.org/10.1016/j. vetpar.2014.02.012 PMID: 24630710

41. Kváč M, Havrdová N, Hlásková L, Daňková T, Kanděra J, Ježková J, et al. Cryptosporidium proliferans n. sp. (Apicomplexa: Cryptosporidiidae): Molecular and Biological Evidence of Cryptic Species within Gastric Cryptosporidium of Mammals. PLoS One. 2016;11(1):e0147090. https://doi.org/10.1371/ journal.pone.0147090 PMID: 26771460

42. Ježková J, Horčičková M, Hlásková L, Sak B, Květoňová D, Novák J, et al. Cryptosporidium testudinis sp. n., Cryptosporidium ducismarci Traversa, 2010 and Cryptosporidium tortoise genotype III (Apicomplexa: Cryptosporidiidae) in tortoises. Folia Parasitol (Praha). 2016;63:63. https://doi.org/10.14411/fp.2016.035 PMID: 27827334

43. Jirků M, Valigurová A, Koudela B, Krízek J, Modrý D, Šlapeta J. New species of Cryptosporidium Tyzzer, 1907 (Apicomplexa) from amphibian host: morphology, biology and phylogeny. Folia Parasitol (Praha). 2008;55(2):81-94. https://doi. org/10.14411/fp.2008.011 PMID: 18666410

44. Valigurová A, Jirků M, Koudela B, Gelnar M, Modrý D, Šlapeta J. Cryptosporidia: epicellular parasites embraced by the host cell membrane. Int J Parasitol. 2008;38(8-9):913-22. https://doi. org/10.1016/j.ijpara.2007.11.003 PMID: 18158154

45. Melicherová J, Ilgová J, Kváč M, Sak B, Koudela B, Valigurová A. Life cycle of Cryptosporidium muris in two rodents with different responses to parasitization. Parasitology. 2014;141(2):287-303. https://doi.org/10.1017/ So031182013001637 PMID: 24128742

46. Holubová N, Sak B, Horčičková M, Hlásková L, Květoňová D, Menchaca S, et al. Cryptosporidium avium n. sp. (Apicomplexa: Cryptosporidiidae) in birds. Parasitol Res. 2016;115(6):2243-51. https://doi.org/10.1007/s00436-016-4967-8 PMID: 26905074

47. Pavlásek I. First record of Cryptosporidium sp. in calves in Czechoslovakia. Folia Parasitol (Praha). 1981;28(2):187-9. PMID: 7239357

48. Pavlásek I. Racek chechtavý (Larus ridibundus L.), nový hostitel Cryptosporidium baileyi (Apicomplexa: Cryptosporidiidae). [The black-headed gull (Larus ridibundus L.), a new host for Cryptosporidium baileyi (Apicomplexa: Cryptosporidiidae)]. Vet Med (Praha). 1993;38(10):629-38. Czech. PMID: 8259642

49. Pavlásek I, Lávicka M, Tůmová E, Skřivan M. Spontánní kryptosporidiová nákaza u odstavených králícat. [Spontaneous Cryptosporidium infection in weaned rabbits]. Vet Med (Praha). 1996;41(12):361-6. Czech. PMID: 9045499

50. Pavlásek I. Nálezy kryptosporidií ve žláznatém žaludku u slepic a u volně žijících a exotických ptákủ odchycených z volné přírody. [First finding of cryptosporidia in glandular stomach of hens and free living and exotic birds]. Veteriářství. 2001:51:103-8. Czech. Available from: http://vetweb.cz/nalezykryptosporidii-ve-zlaznatem-zaludku-u-slepic-a-u-volnezijicich-a-exotickych-ptaku-odchycenych-z-volne-prirody/

51. Pavlásek I. První nález oocyst morfometricky podobných druhům Cryptosporidium muris a C. andersoni u kočky. [First finding of Cryptosporidium oocysts morphological similar to C. muris and C. andersoni in cat]. Veterinarstvi. 2005;55:480-3. Czech. Available from: http://vetweb.cz/prvni-nalez-oocystmorfometricky-podobnych-druhum-cryptosporidium-muris-a-candersoni-u-kocky/

52. Kváč M, Vítovec J. Prevalence and pathogenicity of Cryptosporidium andersoni in one herd of beef cattle. J Vet Med B Infect Dis Vet Public Health. 2003;50(9):451-7. https:// doi.org/10.1046/j.0931-1793.2003.00701.x PMID: 14633200

53. Chroust K. Parazitózy u masných plemen skotu v marginálních oblastech a jejich tlumení. [Parasitosis in beef cattle and their treatment in marginal areas]. Veterinarstvi. 2006;56:430-7. Czech. Available from: http://vetweb.cz/parazitozy-u-masnychplemen-skotu-v-marginalnich-oblastech-a-jejich-tlumeni/ 
54. Kváč M, Kouba M, Vítovec J. Age-related and housingdependence of Cryptosporidium infection of calves from dairy and beef herds in South Bohemia, Czech Republic. Vet Parasitol. 2006;137(3-4):202-9. https://doi.org/10.1016/j. vetpar.2006.01.027 PMID: 16488542

55. Dolejš P, Machula T, Kalousková N, Ditrich O, Půžová G. Odstraňování Cryptosporidium parvum a Giardia intestinalis při úpravě pitných vod. [Removal of Cryptosporidium parvum and Giardia intestinalis from drinking water]. SOVAK. 1999; 8(4):17-19. Czech. Available from: http://www.mzp.cz/ris/aisris-info-copy.nsf/da28f37425da72f7c12569e600723950/81C24 oofo6622697C1256a320035C346?OpenDocument

56. Dolejš P, Ditrich 0 , Machula T. Aktuální poznatky o vývoji problematiky Cryptosporidium sp. u nás a ve světě. [Cryptosporidium sp. in the Czech Republic and world: current knowledge]. Proceedings of Current Issue of Biology in Water Supply; 2000 Feb 2-3; Praha, Czech Republic. p. 134-138. Czech.

57. Dolejš P, Ditrich O, Machula T, Kalousková N, Půžová G. Monitoring of Cryptosporidium and Giardia in Czech drinking water sources. Schriftenr Ver Wasser Boden Lufthyg. 2000;105:147-51. PMID:10842807

58. Dolejš P, Ditrich O, Machula T, Kalousková N, Půžová G. Occurrence and separation of Cryptosporidium oocysts in Drinking Water Treatment. Water Sci Technol. 2000;41(7):159-63. Available from: http://wst.iwaponline.com/ content/41/7/159

59. Epštein J, Kutsar K, Kerbo N, Aro T. Nakkushaiguste esinemine Eestis (statistikaandmed) 16. osa. [Communicable Disease Statistics in Estonia Part 16]. Tallinn: Health Board. 2016. [Accessed 15 Dec 2017]. Estonian. Available from: www. terviseamet.ee/fileadmin/dok/Kasulikku/Nakkushaigused/ Stat_16_2015.pdf

6o. Health Board. Nakkushaigused. [Infectious diseases]. Tallinn: Health Board. 2015. [Accessed 15 Dec 2017]. Estonian. Available from: http://www.terviseamet.ee/nakkushaigused/ nakkushaigustesse-haigestumine.html

61. Šljapnikova L, Pirožkova L, Peetso R, Sudakova R, Zolotuhhina l, Zilmer K, et al. Krüptosporidioos kõhulahtisuse sündroomiga lastel.[Cryptosporidiasis in children with intestinal disorders]. Eesti Arst.1994;3:190-3. Estonian.

62. Lassen B, Ståhl M, Enemark HL. Cryptosporidiosis - an occupational risk and a disregarded disease in Estonia. Acta Vet Scand. 2014a;56(1):36. https://doi.org/10.1186/1751-014756-36 PMID: 24902957

63. Estonian Veterinary and Food Laboratory. Aastaaruanded. [Yearly reports]. Tartu: Estonian Veterinary and Food Laboratory. 2015. [Accessed 15 Dec 2017]. Estonian. Available from: http://www.vetlab.ee/ $? \mathrm{a}=$ page \& page $=42 \mathrm{fo} 88 \mathrm{c} 48 \mathrm{f} 3 \mathrm{e} 323$ aa $1 b b c ? a=$ page $\&$ page $=42$ fo $88 c 48 f_{3 e} 323 a a 1 b b c \&$ subpage $=42$ foa2f 57776 b116a28oe

64. Lassen B, Viltrop A, Järvis T. Herd factors influencing oocyst production of Eimeria and Cryptosporidium in Estonian dairy cattle. Parasitol Res. 2009a;105(5):1211-22. https://doi. org/10.1007/s00436-009-1540-8 PMID: 19557434

65. Lassen B, Viltrop A, Raaperi K, Järvis T. Eimeria and Cryptosporidium in Estonian dairy farms in regard to age, species, and diarrhoea. Vet Parasitol. 2009b;166(3-4):212-9. https://doi.org/10.1016/j.vetpar.2009.08.022 PMID: 19747778

66. Lassen B, Järvis T, Mägi E. Gastrointestinal parasites of sheep on Estonian islands. Agraarteadus: Journal of Agricultural Science. 2013; XXIV(1):7-14. Available from: http://agrt.emu. ee/pdf/2013_1_lassen1.pdf

67. Farkas K, Plutzer J, Moltchanova E, Török A, Varró MJ, Domokos K, et al. Serological responses to Cryptosporidium antigens in inhabitants of Hungary using conventionally filtered surface water and riverbank filtered drinking water. Epidemiol Infect. 2015;143(13):2743-7. https://doi.org/10.1017/ So950268814003859 PMID: 25603318

68. Plutzer J, Törökné A, Szénási Z, Kucsera I, Farkas K, Karanis P. Detection and genotype analysis of Giardia duodenalis from asymptomatic Hungarian inhabitants and comparative findings in three distinct locations. Acta Microbiol Immunol Hung. 2014;61(1):19-26. https://doi.org/10.1556/AMicr.61.2014.1.3 PMID: 24631751

69. Plutzer J, Karanis P. Genotype and subtype analyses of Cryptosporidium isolates from cattle in Hungary. Vet Parasitol. 2007;146(3-4):357-62. https://doi.org/10.1016/j. vetpar.2007.02.030 PMID: 17391853

70. Plutzer J, Tomor B. The role of aquatic birds in the environmental dissemination of human pathogenic Giardia duodenalis cysts and Cryptosporidium oocysts in Hungary. Parasitol Int. 2009;58(3):227-31. https://doi.org/10.1016/j. parint.2009.05.004 PMID: 19446039

71. Szénási Z, Marton S, Kucsera I, Tánczos B, Horváth K, Orosz E, et al. Preliminary investigation of the prevalence and genotype distribution of Giardia intestinalis in dogs in Hungary. Parasitol Res. 2007;101(S1):145-52. https://doi.org/10.1007/s00436007-0622-8 PMID: 17211660

72. Plutzer J, Takó MH, Márialigeti K, Törökné A, Karanis P. First investigations into the prevalence of Cryptosporidium and Giardia spp. in Hungarian drinking water. J Water Health. 2007;5(4):573-84. https://doi.org/10.2166/wh.2007.007 PMID: 17878568

73. Plutzer J, Karanis P, Domokos K, Törökné A, Márialigeti K. Detection and characterisation of Giardia and Cryptosporidium in Hungarian raw, surface and sewage water samples by IFT, PCR and sequence analysis of the SSUrRNA and GDH genes. Int J Hyg Environ Health. 2008;211(5-6):524-33. https://doi. org/10.1016/j.ijheh.2008.04.004 PMID: 18550431

74. Lassen B. The prevalences of Eimeria and Cryptosporidium in large Latvian cattle herds. Vet Med Zoot. 2011;54(76):47-52. Available from: http://vetzoo.Ismuni.lt/data/vols/2011/54/pdf/ lassen.pdf

75. Rożej W, Gołab E, Waloch M, Wąsik M, Sadkowska-Todys M, Czerwiński M, et al. Wystepowanie Cryptosporidium u dziec i osób dorostych z biegunka o nieustalonej etiologii. [The occurrence of Cryptosporidium in a group of children and adults with diarrhoea of undetermined earlier aetiology]. Przegl Epidemiol. 2010;64(1):35-9. Polish. PMID: 20499657

76. Bajer A, Bednarska M, Cacciò SM, Wolska-Kuśnierz B, Heropolitanska-Pliszka E, Bernatowska E, et al. Genotyping of Cryptosporidium isolates from human clinical cases in Poland. Parasitol Res. 2008;103(1):37-42. https://doi.org/10.1007/ S00436-008-0924-5 PMID: 18301922

77. Solarczyk P, Werner A, Majewska AC. Genotypowanie izolatów Giardia duodenalis uzyskanych od ludzi w zachodniocentralnej Polsce. [Genotype analysis of Giardia duodenalis isolates obtained from humans in west-central Poland]. Wiad Parazytol. 2010;56(2):171-7. Polish. PMID: 20707303

78. Bitkowska E, Wnukowska N, Wojtyniak B, Dzbeński TH. Analiza wystepowania pasozytów jelitowych u dzieci klas pierwszych $w$ Polsce w roku szkolnym 2002/2003. [Occurrence of intestinal parasites among first grade students in Poland in years 2002/2003]. Przegl Epidemiol. 2004;58(2):295-302. Polish. PMID: 15517810

79. Zukiewicz M, Kaczmarski M, Topczewska M, Sidor K, Tomaszewska BM. Epidemiological and clinical picture of parasitic infections in the group of children and adolescents from north-east region of Poland. Wiad Parazytol. 2011;57(3):179-87. PMID: 22165741

8o. Sulima P, Werner A, Majewska AC. Occurrence of intestinal protozoan parasite in drinking water supply in Poznańmicroscopic, immunologic and molecular studies. Wiad Parazytol. 2001;47(suppl 2):46.

81. Sroka J, Giżejewski Z, Wójcik-Fatla A, Stojecki K, Bilska-Zając E, Dutkiewicz J, et al. Potential role of beavers (Castor fiber) in contamination of water in the Masurian Lake District (northeastern Poland) with protozoan parasites Cryptosporidium spp. and Giardia duodenalis. Bulletin of the Veterinary Institute in Pulawy. 2015;59(2):219-28. https://doi.org/10.1515/ bvip-2015-0033

82. Matuszewska R, Szczotko M, Krogulska B. Optymalizacja metody wykrywania pierwotniaków pasozytniczych Cryptosporidium i Giardia w środowisku wodnym przy zastosowaniu automatycznej stacji płuczacej Filta-Max xpress. [Optimization of Cryptosporidium and Giardia detection in water environment using automatic elution station Filta-Max xpress]. Rocz Panstw Zakl Hig. 2012;63(4):499-505. Polish. PMID: 23631273

83. Polus M, Kocwa-Haluch R. Occurrence of Cryptosporidium, Giardia and Toxoplasma in surface waters in the area of Cracow. Environment Protection Engineering. 2014;40(2):105-13. Available from: http://yadda. icm.edu.pl/baztech/element/bwmeta1.element. baztech-3d8od27b-cf1b-4a8e-8220-45350d7db20c

84. Sroka J, Stojecki K, Zdybel J, Karamon J, Cencek T, Dutkiewicz J. Occurrence of Cryptosporidium oocysts and Giardia cysts in effluent from sewage treatment plant from eastern Poland. Ann Agric Environ Med. 2013; 20(Spec no 1):57-62. PMID:25000844

85. Nowosad P, Kuczyńska-Kippen N, Słodkowicz-Kowalska A, Majewska AC, Graczyk TK. The use of rotifers in detecting protozoan parasite infections in recreational lakes. Aquat Ecol. 2007;41(1):47-54. https://doi.org/10.1007/s10452-006-9043-5

86. Słodkowicz-Kowalska A, Majewska AC, Rzymski P, Skrzypczak $Ł$, Werner A. Human waterborne protozoan parasites in freshwater bivalves (Anodonta anatina and Unio tumidus) as potential indicators of fecal pollution in urban reservoir. Limnologica. 2015;51:32-6. https://doi.org/10.1016/j. limno.2014.12.001

87. Rzezutka A, Nichols RA, Connelly L, Kaupke A, Kozyra I, Cook N, et al. Cryptosporidium oocysts on fresh produce from areas of high livestock production in Poland. Int J Food 
Microbiol. 2010;139(1-2):96-101. https://doi.org/10.1016/j. ijfoodmicro.2010.01.027 PMID: 20153065

88. Imre K. Contribuții la cunoașterea biologiei, epidemiologiei, diagnosticului și controlului criptosporidiozei în vestul României. [Contributions in the knowledge of biology, epidemiology, diagnosis and control of cryptosporidiosis in Western Romania]. [dissertation]. Timișoara: Banat's University of Agricultural Sciences and Veterinary' Medicine 'King Michael I of Romania' from Timisoara, Faculty of Veterinary Medicine; 2010. Romanian. Available from: http://www.usab-tm.ro/ rezumat/Imre\%20doc.\%20teza\%2opdf\%2oengleza\%20(1).pdf

89. Vieira PM, Mederle N, Lobo LM, Imre K, Mederle O, Xiao L, Dărăbuş G, Matos O. Molecular characterization of Cryptosporidium (Apicomplexa) in children and cattle in Romania. Folia Parasitol (Praha). 2015;62:002. https://doi.org/ http://dx.doi.org/10.14411/fp.2015.002 PMID:25960546

90. Neghina R, Neghina AM, Marincu I, Moldovan R, Iacobiciu I. Foodborne nematodal infections in hospitalized patients from a southwestern Romanian county. Foodborne Pathog Dis. 2010;7(8):975-80. https://doi.org/10.1089/fpd.2010.0533 PMID: 20455753

91. Costache C, Colosi I, Anca L. Human giardiosis report in Romania: the principle of snowball. Proceedings of the XIth European Multicolloquium of Parasitology; 2012 Jul 25-29; Cluj-Napoca, Romania. Available from: http://www.zooparaz. net/emop11/

92. Imre K, Lobo LM, Matos O, Popescu C, Genchi C, Dărăbuş G. Molecular characterisation of Cryptosporidium isolates from pre-weaned calves in Romania: is there an actual risk of zoonotic infections? Vet Parasitol. 2011;181(2-4):321-4. https://doi.org/10.1016/j.vetpar.2011.04.042 PMID: 21612871

93. Imre K, Luca C, Costache M, Sala C, Morar A, Morariu S, et al. Zoonotic Cryptosporidium parvum in Romanian newborn lambs (Ovis aries). Vet Parasitol. 2013;191(1-2):119-22. https://doi. org/10.1016/j.vetpar.2012.08.020 PMID: 22995338

94. Sorescu DI. Studiul giardiozei la animale în zona de vest și sud-vest a României. [The study of giardiosis in Western and South-Western of Romania]. [dissertation]. Timişoara: Banat's University of Agricultural Sciences and Veterinary Medicine ‘King Michael I of Romania' from Timişoara, Faculty of Veterinary Medicine; 2013. Romanian.

95. Bejan A. Criptosporidioza vițeilor și iezilor: cercetări privind diagnosticul, epidemiología, și etiopatogeneza bolii. [Cryptosporidiosis in calves and goat kids: research concerning diagnosis, epidemiology, and etiopathogenesis]. [dissertation]. Cluj-Napoca: University of Agricultural Sciences and Veterinary Medicine Cluj-Napoca, Faculty of Veterinary Medicine; 2009. Romanian. Available from: http://usamvcluj. ro/files/teze/bejan.pdf

96. Imre K, Sala C, Morar A, Ilie MS, Plutzer J, Imre M, et al. Giardia duodenalis and Cryptosporidium spp. as contaminant protozoa of the main rivers of western Romania: genetic characterization and public health potential of the isolates. Environ Sci Pollut Res Int. 2017;24(22):18672-9. https://doi.org/http://dx.doi. org/ 10.1007/S11356-017-9543-y PMID:28653194

97. Imre K, Morar A, Ilie MS, Plutzer J, Imre M, Emil T, et al. Survey of the occurrence and human infective potential of Giardia duodenalis and Cryptosporidium spp. in wastewater and different surface water sources of western Romania. Vector Borne Zoonotic Dis. 2017;17(10):685-91. https://doi. org/10.1089/vbz.2017.2155 PMID: 28832257

98. Gozdenović E, Mitrović N, Dakić Z, Stojković-Švirtlih N, Dulović O. [Family outbreak of cryptosporidiosis in Serbia: case report]. Srp Arh Celok Lek. 2012;140(9-10):653-7. https://doi. org/10.2298/SARH1210653G PMID: 23289286

99. Korać M. Uticaj visoko aktivne antiretrovirusne terapije na oboljenja gastrointestinalnog trakta kod bolesnika sa sindromom stečene imunodeficijencije. [The impact of highly active antiretroviral therapy on diseases of the gastrointestinal tract in patients with acquired immunodeficiency syndrome]. [dissertation]. Belgrade: School of Medicine, University of Belgrade; 2009. Serbian.

100. Institute of Public Health of Serbia. 'Dr Milan Jovanovic Batut'. [Annual Reports on Infectious Diseases in Serbia 2005-2014]. Belgrade: Institute of Public Health of Serbia 'Dr Milan Jovanovic Batut'. [Accessed 12 Dec 2017]. Available from: http://www.batut.org.rs/index.php?category_id=140

101. Miladinović Tasić N. Dijagnostički I epidemiološki aspekti prisustva protozoa Giardia lamblia u digestivnom traktu. [Diagnostic and epidemiological aspects of Giardia lamblia presence in the digestive tract]. [dissertation]. Nis: School of Medicine, University of Nis; 2006. Serbian.

102. Miladinović Tasić N, Tasić S, Kranjčić-Zec I, Tasić G, Tasić A. Asymptomatic giardiasis - more prevalent in refugees than in native inhabitants of the city of Nis, Serbia. Cent Eur J Med. 2008;3(2):203-6. https://doi.org/10.2478/s11536-008-0013-2
103. Miladinović Tasić N, Tasić S, Tasić A, Zdravković D, Đorđević J, Micić T. Advantages of enzyme immunoassay in diagnosing lambliosis of population under sanitary supervision. Acta Facultatis Medicae Naissensis. 2010;27(1):337. Available from: https://pdfs.semanticscholar.org/3202/8fd 4 cd45fdo418bcfe476eb90acb86f8bdco.pdf

104. Nikolić A, Klun I, Bobić B, Ivović V, Vujanić M, Zivković $\mathrm{T}$, et al. Human giardiasis in Serbia: asymptomatic vs symptomatic infection. Parasite. 2011;18(2):197-201. https:// doi.org/10.1051/parasite/2011182197 PMID: 21678797

105. Nikolić A, Bobić B, Katić-Radivojević S, Klun I, DjurkovićDjaković 0. Giardia infection in humans and pets in Serbia. In: Mas-Coma S, editor. Multidisciplinarity for Parasites Vectors and Parasitic Diseases: Proceedings of the IX European Multicolloquium of Parasitology, Vol 2; 2004 Jul 18-23; Valencia, Spain. Bologna: Medimond; 2004. p. 179-183.

106. Spahić Š. Učestalost crevnih parazita u školske dece u opštini Novi Pazar u odnosu na životnu sredinu i konfesionalnu pripadnost. [Intestinal parasitic infections in schoolchildren in Novi Pazar in relation to the environment and confessional affiliation]. [MS thesis]. Belgrade: Military Medical Academy, Belgrade; 2006. Serbian.

107.Mišić Z, Katić-Radivojević S, Kulišić Z. Cryptosporidium infection in weaners, bull calves and postparturient cows in the Belgrade area. Acta Vet (Beogr). 2002;52(1):37-42. https:// doi.org/10.2298/AVB0201037M

108. Mišić Z, Abe N. Subtype analysis of Cryptosporidium parvum isolates from calves on farms around Belgrade, Serbia and Montenegro, using the $60 \mathrm{kDa}$ glycoprotein gene sequences. Parasitology. 2007;134(3):351-8. https://doi. org/10.1017/S0031182006001508 PMID: 17076920

109. Mišić Z, Katić-Radivojević S, Kulišić Z. Cryptosporidium infection in nursing, weaning and post-weaned piglets and sows in the Belgrade district Serbia. Acta Vet (Beogr) 2003;53(5-6):361-6. https://doi.org/10.2298/AVB0306361M

110. Nikolić A, Dimitrijević S, Katić-Radivojević S, Klun I, Bobić B, Djurković-Djaković 0 . High prevalence of intestinal zoonotic parasites in dogs from Belgrade, Serbia--short communication. Acta Vet Hung. 2008;56(3):335-40. https://doi.org/10.1556/ AVet.56.2008.3.7 PMID: 18828485

111. Sommer MF, Beck R, lonita M, Stefanovska J, Vasić A, Zdravković N, et al. Multilocus sequence typing of canine Giardia duodenalis from South Eastern European countries. Parasitol Res. 2015;114(6):2165-74. https://doi.org/10.1007/ s00436-015-4405-3 PMID: 25804971

112. Nikolić A, Dimitrijević S, Djurković-Djaković O, Bobić B, Maksimović-Mihajlović 0 . Giardiasis in dogs and cats in the Belgrade area. Acta Vet (Beogr). 2002;52(1):43-8. https://doi. org/10.2298/AVBo201043N

113. Lažetić V, Ilić T, Ilić V, Dimitrijević S. Parazitske bolesti mačaka na beogradskom Području sa posebnim osvrtom na zoonoze. [Parasitic diseases in cats in Belgrade area with special emphasis on zoonoses]. Arhiv veterinarske medicine. 2012; 5(2):53-66. Serbian. Available from: http://niv.ns.ac.rs/ StariSajt/tr31084/fajlovi/12/78.pdf

114. National Institute of Public Health of the Republic of Slovenia. Epidemiološko spremljanje nalezljivih bolezni v Sloveniji. Leta 2003-2015. [Annual Epidemiological Report on Communicable Diseases in Slovenia. Years 2003-2015]. Ljubljana: National Institute of Public Health. [Accessed 18 Dec 2017]. Slovenian. Available from: http://www.nijz.si/ sl/epidemiolosko-spremljanje-nalezljivih-bolezni-letna-incetrtletna-porocila

115. Šoba B, Islamović S, Skvarč M, Caccio SM. Multilocus genotyping of Giardia duodenalis (Lambl, 1859) from symptomatic human infections in Slovenia. Folia Parasitol (Praha). 2015;62:062. https://doi.org/http://dx.doi. org/10.14411/fp.2015.062 PMID:26580803

116. Stantic-Pavlinic M, Xiao L, Glaberman S, Lal AA, Orazen T, Rataj-Verglez A, et al. Cryptosporidiosis associated with animal contacts. Wien Klin Wochenschr. 2003;115(3-4):125-7. https://doi.org/10.1007/BF03040292 PMID: 12674690

117. Soba B, Logar J. Genetic classification of Cryptosporidium isolates from humans and calves in Slovenia. Parasitology. 2008;135(11):1263-70. https://doi.org/10.1017/ So031182008004800 PMID: 18664309

118. Van Lith L, Šoba B, Vizcaino VV, Svard S, Sprong H, Tosini F, et al. A real-time assemblage-specific PCR assay for the detection of Giardia duodenalis assemblages A, B and E in fecal samples. Vet Parasitol. 2015;211(1-2):28-34. https://doi. org/10.1016/j.vetpar.2015.04.017 PMID: 25935292

119. Kváč M, Hromadová N, Květoňová D, Rost M, Sak B. Molecular characterization of Cryptosporidium spp. in pre-weaned dairy calves in the Czech Republic: absence of $C$. ryanae and management-associated distribution of C. andersoni, C. bovis 
and C. parvum subtypes. Vet Parasitol. 2011;177(3-4):378-82. https://doi.org/10.1016/j.vetpar.2010.11.048 PMID: 21168973

120. Guzman-Herrador B, Carlander A, Ethelberg S,

Freiesleben de Blasio B, Kuusi M, Lund V, et al. Waterborne outbreaks in the Nordic countries, 1998 to 2012. Euro Surveill. 2015;20(24):21160. https://doi.org/10.2807/1560-7917. ES2015.20.24.21160 PMID: 26111239

121. Cacciò SM, Chalmers RM. Human cryptosporidiosis in Europe. Clin Microbiol Infect. 2016;22(6):471-80. https://doi. org/10.1016/j.cmi.2016.04.021 PMID: 27172805

122. Ryan U, Xiao L, Read C, Zhou L, Lal AA, Pavlásek I. Identification of novel Cryptosporidium genotypes from the Czech Republic. Appl Environ Microbiol. 2003;69(7):43027. https://doi.org/10.1128/AEM.69.7.4302-4307.2003 PMID: 12839819

123. Ondráčková Z, Kváč $M$, Sak B, Květoňová $D$, Rost $M$. Prevalence and molecular characterization of Cryptosporidium spp. in dairy cattle in South Bohemia, the Czech Republic. Vet Parasitol. 2009;165(1-2):141-4. https://doi.org/10.1016/j. vetpar.2009.06.035 PMID: 19616383

124. Kváč M, Sak B, Hanzlíková D, Kotilová J, Květoňová D. Molecular characterization of Cryptosporidium isolates from pigs at slaughterhouses in South Bohemia, Czech Republic. Parasitol Res. 2009c;104(2):425-8. https://doi.org/10.1007/ S00436-008-1215-X PMID: 18850112

125. Kváč $M$, Hanzlíková $D$, Sak $B$, Květoňová D. Prevalence and age-related infection of Cryptosporidium suis, C. muris and Cryptosporidium pig genotype II in pigs on a farm complex in the Czech Republic. Vet Parasitol. 2009a;16o(3-4):319-22. https://doi.org/10.1016/j.vetpar.2008.11.007 PMID: 19091471

126. Jeníková $M$, Němejc K, Sak B, Květoňová D, Kváč M. New view on the age-specificity of pig Cryptosporidium by speciesspecific primers for distinguishing Cryptosporidium suis and Cryptosporidium pig genotype II. Vet Parasitol. 2011;176(23):120-5. https://doi.org/10.1016/j.vetpar.2010.11.010 PMID: 21131129

127. Němejc K, Sak B, Květoňová $D$, Hanzal V, Janiszewski $P$, Forejtek P, et al. Cryptosporidium suis and Cryptosporidium scrofarum in Eurasian wild boars (Sus scrofa) in Central Europe. Vet Parasitol. 2013a;197(3-4):504-8. https://doi. org/10.1016/j.vetpar.2013.07.003 PMID: 23916060

128. Wagnerová P, Sak B, McEvoy J, Rost M, Matysiak AP, Ježková J, et al. Genetic diversity of Cryptosporidium spp. including novel identification of the Cryptosporidium muris and Cryptosporidium tyzzeri in horses in the Czech Republic and Poland. Parasitol Res. 2015;114(4):1619-24. https://doi. org/10.1007/s00436-015-4353-y PMID: 25722018

129. Holubová N, Sak B, Horčičková M, Hlásková L, Květoňová D, Menchaca S, et al. Cryptosporidium avium n. sp. (Apicomplexa: Cryptosporidiidae) in birds. Parasitol Res. 2016;115(6):2243-51. https://doi.org/10.1007/s00436-0164967-8 PMID: 26905074

130. Němejc K, Sak B, Květoňová D, Hanzal V, Jeníková M, Kváč M. The first report on Cryptosporidium suis and Cryptosporidium pig genotype II in Eurasian wild boars (Sus scrofa) (Czech Republic). Vet Parasitol. 2012;184(2-4):122-5. https://doi.org/10.1016/j.vetpar.2011.08.029 PMID: 21917378

131. Němejc K, Sak B, Květoňová D, Kernerová N, Rost $M$, Cama VA, et al. Occurrence of Cryptosporidium suis and Cryptosporidium scrofarum on commercial swine farms in the Czech Republic and its associations with age and husbandry practices. Parasitol Res. 2013b;112(3):1143-54. https://doi.org/10.1007/ s00436-012-3244-8 PMID: 23271566

132. Kodádková A, Kvác M, Ditrich O, Sak B, Xiao L. Cryptosporidium muris in a reticulated giraffe (Giraffa camelopardalis reticulata). J Parasitol. 2010;96(1):211-2. https://doi.org/10.1645/GE-2212.1 PMID: 19685941

133. Kotková $M$, Němejc K, Sak B, Hanzal V, Květonová D, Hlásková L, et al. Cryptosporidium ubiquitum, C. muris and Cryptosporidium deer genotype in wild cervids and caprines in the Czech Republic. Folia Parasitol (Praha). 2016;63:63. https://doi.org/10.14411/fp.2016.003 PMID: 26857135

134. Máca O, Pavlásek I. First finding of spontaneous infections with Cryptosporidium baileyi and $C$. meleagridis in the red-legged partridge Alectoris rufa from an aviary in the Czech Republic. Vet Parasitol. 2015;209(3-4):164-8. https:// doi.org/10.1016/j.vetpar.2015.03.003 PMID: 25814162

135. Máca O, Pavlásek I. Cryptosporidium infections of ringnecked pheasants (Phasianus colchicus) from an intensive artificial breeding programme in the Czech Republic. Parasitol Res. 2016;115(5):1915-22. https://doi.org/10.1007/s00436-0164933-5 PMID: 26815038

136. Kváč M, McEvoy J, Loudová M, Stenger B, Sak $B$, Květoňová $D$, et al. Coevolution of Cryptosporidium tyzzeri and the house mouse (Mus musculus). Int J
Parasitol. 2013b;43(10):805-17. https://doi.org/10.1016/j. ijpara.2013.04.007 PMID: 23791796

137. Hůrková L, Hajdusek O, Modrý D. Natural infection of Cryptosporidium muris (Apicomplexa: Cryptosporiidae) in Siberian chipmunks. J Wildl Dis. 2003;39(2):441-4. https://doi. org/10.7589/0090-3558-39.2.441 PMID: 12910775

138. Hofmannová L, Hauptman K, Huclová K, Květoňová D, Sak B, Kváč M. Cryptosporidium erinacei and C. parvum in a group of overwintering hedgehogs. Eur J Protistol. 2016;56(56):15-20. https://doi.org/10.1016/j.ejop.2016.05.002 PMID: 27344109

139. Kváč M, Hořická A, Sak B, Prediger J, Salát J, Širmarová J, et al. Novel Cryptosporidium bat genotypes III and IV in bats from the USA and Czech Republic. Parasitol Res. 2015;114(10):3917-21. https://doi.org/10.1007/s00436-0154654-1 PMID: 26255170

140. Zemanová I, Husník R, Svobodová V. Giardia intestinalis u psů - výskyt, zoonotický potenciál a využití endoskopické diagnostiky. [Giardia intestinalis in dogs - occurrence, zoonotic potential and use of endoscopic diagnostic]. Veterinarstvi. 2005;55:319-25. Czech. Available from: http:// vetweb.cz/giardia-intestinalis-u-psu-vyskyt-zoonotickypotencial-a-vyuziti-endoskopicke-diagnostiky/

141. Dubná S, Langrová I, Nápravník J, Jankovská I, Vadlejch J, Pekár S, et al. The prevalence of intestinal parasites in dogs from Prague, rural areas, and shelters of the Czech Republic. Vet Parasitol. 2007;145(1-2):120-8. https://doi.org/10.1016/j. vetpar.2006.11.006 PMID: 17169492

142. Strnadová P, Svobodová V, Vernerová E. Protozoální infekce jehňat a kůzlat na farmách v České republice. [Protozoal infections of lambs and goats on farms in the Czech Republic]. Veterinarstvi. 2008;58:451-8. Czech. Available from: http://vetweb.cz/protozoalni-infekce-jehnat-a-kuzlat-nafarmach-v-ceske-republice/

143. Pavlásek I, Hess L, Stehlík I. Stika V. První nálezy Giardia spp. u koní v České republice. [First finding of Giardia spp. in horses in the Czech Republic]. Veterinární medicína. 1995;40(3):81-6. Czech. Available from: http://www.medvik. cz/link/bmc96002788

144. Pavlásek I, Nágl I, Vácha J, Lávicka M. První nálezy Giardia spp. u srnce obecného (Capreolus capreolus L.). [The first finding of Giardia spp. in roebucks (Capreolus capreolus L.)]. Vet Med (Praha). 1993;38(6):381-4. Czech. PMID: 8346624

145. Stojecki K, Sroka J, Cacciò SM, Cencek T, Dutkiewicz J, Kusyk P. Prevalence and molecular typing of Giardia duodenalis in wildlife from eastern Poland. Folia Parasitol. 2015;62:042. https://doi.org/http://dx.doi.org/10.14411/ fp.2015.042

146. Stojecki K, Sroka J, Cencek T, Dutkiewicz J. Epidemiological survey in Łęczyńsko-Włodawskie Lake District of eastern Poland reveals new evidence of zoonotic potential of Giardia intestinalis. Ann Agric Environ Med. 2015b;22(4):594-8. https://doi.org/10.5604/12321966.1185759 PMID: 26706961

147. Rzeżutka A, Kaupke A. Occurrence and molecular identification of Cryptosporidium species isolated from cattle in Poland. Vet Parasitol. 2013;196(3-4):301-6. https://doi.org/10.1016/j. vetpar.2013.03.009 PMID: 23566407

148. Rzeżutka A, Kaupke A, Kozyra I, Pejsak Z. Molecular studies on pig cryptosporidiosis in Poland. Pol J Vet Sci. 2014;17(4):577-82. https://doi.org/10.2478/pjvs-2014-0086 PMID: 25638969

149. Majewska AC, Solarczyk P, Tamang L, Graczyk TK. Equine Cryptosporidium parvum infections in western Poland. Parasitol Res. 2004;93(4):274-8. https://doi.org/10.1007/ s00436-004-1111-y PMID: 15156396

150. Majewska AC, Werner A, Sulima P, Luty T. Prevalence of Cryptosporidium in sheep and goats bred on five farms in west-central region of Poland. Vet Parasitol. 2000;89(4):26975. https://doi.org/10.1016/S0304-4017(00)00212-0 PMID: 10799840

151. Jaros D, Zygner W, Jaros S, Wędrychowicz H. Detection of Giardia intestinalis assemblages A, B and D in domestic cats from Warsaw, Poland. Pol J Microbiol. 2011;60(3):259-63. PMID: 22184934

152. Zygner W, Jaros D, Skowrońska M, Bogdanowicz Kamirska M, Wedrychowicz H. [Prevalence of Giardia intestinalis in domestic dogs in Warsaw]. Wiad Parazytol. 2006;52(4):311-5. Polish. PMID: 17432624

153. Solarczyk P, Majewska AC. A survey of the prevalence and genotypes of Giardia duodenalis infecting household and sheltered dogs. Parasitol Res. 2010;106(5):1015-9. https://doi. org/10.1007/s00436-010-1766-5 PMID: 20155370

154. Bajer A, Bednarska M. Cryptosporidium spp. and Giardia spp. infections in sled dogs. Med Weter. 2007;63:681-7. Polish. Available from: http://medycynawet.edu.pl/index.php/ archives/121/1278-summary-medycyna-wet-63-6-681-687-2007 
155.Majewska AC, Graczyk TK, Słodkowicz-Kowalska A, Tamang

$L$, Jedrzejewski S, Zduniak P, et al. The role of free-

ranging, captive, and domestic birds of Western Poland

in environmental contamination with Cryptosporidium

parvum oocysts and Giardia lamblia cysts. Parasitol Res.

2009;104(5):1093-9. https://doi.org/10.1007/s00436-0081293-9 PMID: 19050920

156. Paziewska A, Bednarska M, Niewegłowski H, Karbowiak G, Bajer A. Distribution of Cryptosporidium and Giardia spp. in selected species of protected and game mammals from NorthEastern Poland. Ann Agric Environ Med. 2007;14(2):265-70. PMID: 18247463

157. Majewska AC, Solarczyk P, Moskwa B, Cabaj W, Jankowska W, Nowosad P. Giardia prevalence in wild cervids in Poland. Ann Parasitol. 2012;58(4):207-9. PMID: 23914615

158. Perec-Matysiak A, Buńkowska-Gawlik K, Zaleśny $G$, Hildebrand J. Small rodents as reservoirs of

Cryptosporidium spp. and Giardia spp. in south-western Poland. Ann Agric Environ Med. 2015;22(1):1-5. https://doi. org/10.5604/12321966.1141359 PMID: 25780818

159. Kloch A, Bajer A. Natural infections with Cryptosporidium in the endangered spotted souslik (Spermophilus suslicus). Acta Parasitol. 2012;57(1):13-9. https://doi.org/10.2478/ S11686-012-0006-9 PMID: 22807009

160. Bajer A. Between-year variation and spatial dynamics of Cryptosporidium spp. and Giardia spp. infections in naturally infected rodent populations. Parasitology. 2008;135(14):162949. https://doi.org/10.1017/So031182008004952 PMID: 18992178

161.Pilarczyk B, Smugata M, Binerowska B, Tomza-Marciniak A, Bakowska M, Tylkowska A. Prevalence of intestinal parasites of Polish Konik horses - comparison between domestic horses and imported from the Netherlands. Bulletin of the Veterinary Institute in Pulawy. 2010;54:171-4.

162. Mircean V, Györke A, Cozma V. Prevalence and risk factors of Giardia duodenalis in dogs from Romania. Vet Parasitol. 2012;184(2-4):325-9. https://doi.org/10.1016/j. vetpar.2011.08.022 PMID: 21899952

163. Adriana G, Zsuzsa K, Mirabela Oana D, Mircea GC Viorica M. Giardia duodenalis genotypes in domestic and wild animals from Romania identified by PCR-RFLP targeting the gdh gene. Vet Parasitol. 2016;217:71-5. https://doi.org/10.1016/j. vetpar.2015.10.017 PMID: 26827864

164. Mircean V, Titilincu A, Vasile C. Prevalence of endoparasites in household cat (Felis catus) populations from Transylvania (Romania) and association with risk factors. Vet Parasitol. 2010;171(1-2):163-6. https://doi.org/10.1016/j. vetpar.2010.03.005 PMID: 20381250

165. Mircean V, Györke A, Jarca A, Cozma V. Prevalence of Giardia species in stool samples by ELISA in household cats from Romania and risk factors. J Feline Med Surg. 2011;13(6):479-82. https://doi.org/10.1016/j.jfms.2011.01.003 PMID: 21334236

166. Lalošević V, Lalošević D, Terzić M. Prevalenca kriptosporidioze kod domaćih životinja. Letopis naučnih radova. [Prevalence of cryptosporidiosis in domestic animals]. 2007;31(1):153-7. Serbian. Available from: http://scindeksclanci.ceon.rs/data/pdf/0546-8264/2007/0546-82640701153L. pdf

167. Mišić Z, Katić-Radivojević S, Kulišić Z. Cryptosporidium infection in lambs and goat kids in Serbia. Acta Vet (Beogr). 2006;56(1):49-54. https://doi.org/10.2298/AVBo601049M

168. Šoba B, Petrovec M, Mioč V, Logar J. Molecular characterisation of Cryptosporidium isolates from humans in Slovenia. Clin Microbiol Infect. 2006;12(9):918-21. https://doi. org/10.1111/j.1469-0691.2006.01465.x PMID: 16882299

\section{License and copyright}

This is an open-access article distributed under the terms of the Creative Commons Attribution (CC BY 4.0) Licence. You may share and adapt the material, but must give appropriate credit to the source, provide a link to the licence, and indicate if changes were made.

This article is copyright of the authors, 2018. 